\title{
Etapas históricas de la relación entre el Fondo Monetario Internacional y América Latina $(1944-2015)^{*}$
}

\section{Historical Stages of the Relationship between the International Monetary Fund and Latin America (1944-2015)}

\author{
Pablo Nemiña \\ Consejo Nacional de Investigaciones Científicas y Técnicas, Argentina, \\ pablonemina@yahoo.com.ar \\ Juan Larralde \\ Banco Central de la República Argentina, Argentina, jlarralde@gmail.com
}

Resumen. El trabajo propone un análisis de historia económica sobre la relación entre el Fondo Monetario Internacional (FMI) y los países de América Latina en el periodo que va desde 1944 hasta 2015. Existen importantes antecedentes del estudio sobre la relación a escala nacional; no obstante, se observa un vacío en lo que respecta al análisis del vínculo en el ámbito regional. Se plantea que la orientación política del FMI y los gobiernos, el contexto macroeconómico y las ideas económicas reinantes constituyen elementos decisivos para comprender la configuración que asume la relación entre el FMI y las naciones latinoamericanas. Pueden identificarse seis etapas históricas en función de los lineamientos centrales de las políticas económicas y las características de los créditos y condiciones que exigía el organismo, algunas de intenso acercamiento, como sucedió en las décadas de 1980 y 1990, y otras de mayor distancia, como en la década pasada.

Palabras clave: Fondo Monetario Internacional; condicionalidad; crédito; relaciones monetarias internacionales.

Abstract. This paper proposes an Economic History analysis of the relationship between the International Monetary Fund (IMF) and Latin American countries during the period from 1944 to 2015 . Although there are important antecedents of the analysis of the relationship at the national level, there is a void in relation to the analysis of the link at the regional level. It is suggested that the political orientation of the IMF and the governments, the macroeconomic context, and the prevailing economic ideas are decisive elements to understand the configuration of the relationship between the IMF

* Una versión previa de este trabajo se presentó en el V Congreso Latinoamericano de Historia Económica, en São Paulo, Brasil, del 19 al 21 de julio de 2016. 
and Latin American nations. Six historical stages can be identified according to the central guidelines of the implemented economic policies and the characteristics of the credits and conditions required by the organism, some of them of intense approach as during the $80 \mathrm{~s}$ and $90 \mathrm{~s}$, and others of greater distance as in the past decade.

Keywords: International Monetary Fund; conditionality; credit; international monetary relations.

JEL: L62; F59; P16; E247.

Fecha de recepción: 30 de enero de 2017. Fecha de aceptación: 31 de julio de 2017.

Patrocinio: Consejo Nacional de Investigaciones Científicas y Técnicas; Universidad Nacional de San Martín; Facultad Latinoamericana de Ciencias Sociales, Argentina; Universidad de Buenos Aires; Banco Central de la República Argentina.

Agradecimientos: a Diana Tussie y a los evaluadores anónimos por sus comentarios; naturalmente, se los exime de toda responsabilidad en cuanto a los errores u omisiones existentes.

\title{
INTRODUCCIÓN
}

\begin{abstract}
i la restricción externa que lleva al recurrente endeudamiento externo - constituye un obstáculo estructural para el desarrollo económico en la periferia, se comprende que el organismo encargado de proporcionar financiamiento frente a las crisis de balanza de pagos haya tenido una presencia extendida en los países en desarrollo desde hace más de medio siglo. Por medio de sus créditos condicionados, el FMI ha tenido un papel central en la promoción de las reformas de mercado, inspiradas en el pensamiento económico neoclásico.

La relación del FMI con América Latina ${ }^{1}$ es particularmente destacable por varios motivos. Primero, la región ingresó rápida y masivamente al organismo. Durante los dos primeros años de su fundación todos los países se incorporaron al organismo, con excepción de Haití y Argentina, ${ }^{2}$ que ingresaron en 1953 y 1956 respectivamente, y en las décadas siguientes se incorporaron las naciones del Caribe. En la actualidad, toda América La-
\end{abstract}

\footnotetext{
${ }^{1}$ De acuerdo con la CEPAL (2017), América Latina es la región que agrupa a los 20 países cuya lengua oficial es el español o el portugués, más Haití.

${ }^{2}$ La evidencia reciente muestra que poco después de asumir su primera presidencia, Perón no sólo estuvo interesado en que Argentina ingresara a los gemelos de Bretton Woods, sino que llevó adelante varias negociaciones reservadas para lograr tal objetivo. Pero la negativa de Estados Unidos a aceptar el ingreso del que consideraba un país populista y la poca disposición del gobierno argentino a otorgar concesiones determinaron el fracaso de tales conversaciones (Kedar, 2012).
} 
tina y el Caribe son miembros del FMI, a excepción de Cuba, que se retiró después de la crisis de los misiles.

Por otra parte, a pesar de ser los usuarios más frecuentes de los préstamos del Fondo, los países de la región no han evitado atravesar por periodos de muy alta volatilidad macroeconómica (Hutchison y Noy, 2003, p. 992). Mientras algunos señalan la tasa de incumplimiento de dichos programas como la causa de este fracaso (Dreher, 2009), otros apuntan al diseño deficiente de los programas (Ghosh, 2013) o a un enfoque macroeconómico que no atiende las particularidades de las economías periféricas (Woods, 2006).

Por último, la intervención del Fondo no se limitó a las crisis. Si bien durante los periodos de crisis de balanza de pagos el FMI aumenta sus desembolsos, durante periodos de estabilidad financiera algunos países convocaron al organismo para proveer asistencia técnica o para suscribir acuerdos precautorios que sirvieran como señal ante los inversores privados (Stiglitz, 2002).

Desde el inicio de la crisis de la deuda, en la década de 1980, diversos autores estudiaron desde la historia económica y la economía política la relación entre el FMI y algunos países de América Latina, cuyo vínculo se mostró particularmente conflictivo en términos políticos, como Argentina (Brenta, 2013; Kedar, 2013; Nemiña, 2013), Brasil (Almeida, 2004), Jamaica (Bernal, 1984), México (Suárez, 1994) y Perú (Scheetz, 1986). ${ }^{3}$ Otros analizaron la coordinación entre el FMI con los bancos comerciales acreedores (Devlin, 1989) y la ineficacia de los acuerdos de condicionalidad alta para restablecer el crecimiento en contextos de endeudamiento extremo (Sachs, 1989). El impacto social de los programas de ajuste estructural también alentó a varios autores a analizar la intervención del organismo en la región como un todo (Lichtensztejn y Baer, 1989; ${ }^{4}$ Pastor, 1987; Remmer, 1986); sin embargo, las décadas siguientes mostraron un hiato en esa producción. A partir del estallido de la crisis financiera global en 2008 se revitalizó esta línea de investigación con base en los trabajos de Frenkel y Avenburg (2009), cuyo análisis no abarca el periodo posterior a la crisis global, y Ugarteche (2016), quien desarrolla una historia episódica muy relevante, que abrevia el estudio diacrónico sistemático.

En el presente artículo continuamos esta línea de indagación, que resalta la relevancia de profundizar el análisis del vínculo entre el FMI y América Latina en el ámbito regional, apoyado en diversas fuentes bi-

\footnotetext{
${ }^{3}$ Cabe mencionar los trabajos que estudian la relación del FMI, el Banco Mundial y el sector financiero con Colombia y Chile (Kofas, 2002) y Argentina (García, 2008) desde la década de 1950 hasta la crisis de Bretton Woods.

${ }^{4}$ Esta obra posee el mérito de ser el primer trabajo de indagación sistemática realizado en el Sur.
} 
bliográficas ${ }^{5}$ y series estadísticas oficiales; además analizamos la evolución histórica de la relación entre el Fondo y la región, desde sus comienzos hasta la actualidad. Se propone que la orientación política del FMI y los gobiernos, el contexto macroeconómico y las ideas económicas predominantes constituyen elementos decisivos para comprender la configuración que asume la conexión entre el FMI y las naciones latinoamericanas, a partir de la cual pueden identificarse seis etapas históricas. El trabajo se divide en seis secciones, cada una correspondiente a una etapa en función de la lógica política del vínculo y su relevancia para la gobernanza financiera. $\mathrm{El}$ trabajo concluye con un apartado de reflexiones finales.

\section{ORTODOXIA VERSUS ESTRUCTURALISMO DURANTE EL RÉGIMEN DE BRETTON WOODS}

Hacia finales de la segunda guerra mundial se estableció el consenso keynesiano, que marcó las estrategias para el desarrollo económico en los países en desarrollo capitalistas durante los siguientes 25 años. Diferenciado tanto de la economía de libre mercado como de la planificación centralizada, el consenso keynesiano promovía una planificación macroeconómica orientativa, cuyo fin era alcanzar el nivel de demanda global efectiva correspondiente al equilibrio con pleno empleo, recurriendo -de ser necesario- a la inversión pública. Una vez logrado el pleno empleo, la asignación de los recursos se realizó por medio de mecanismos de mercado, aunque sujetos a una fuerte regulación del Estado. El consenso keynesiano también promovía el crecimiento basado en el mercado interno, dado el énfasis puesto en los Estados nacionales como promotores del pleno empleo en el ámbito local y, en el caso de los países en desarrollo, el pesimismo respecto de la evolución de las exportaciones de productos primarios (Singer, 1997).

En este marco, durante las negociaciones de Bretton Woods, en las cuales se discutió el orden económico de la posguerra, se expresó un acuerdo sobre la necesidad de evitar fluctuaciones cambiarias bruscas y promover un crecimiento equilibrado con pleno empleo, para lo cual se establecieron controles en los movimientos de capital (Eichengreen, 2000). Si bien fueron lideradas por Estados Unidos y el Reino Unido, la presencia de diferentes delegaciones de países de la periferia, en especial

\footnotetext{
${ }^{5}$ Se realizó un extenso relevamiento de las fuentes bibliográficas que estudian de manera directa la relación entre el FMI y América Latina como región, el cual fue complementado con estudios de casos nacionales relevantes y varios trabajos que analizan el comportamiento del FMI en diferentes etapas históricas, sin ceñirse necesariamente a regiones determinadas.
} 
de América Latina, motivó que se pusiera un énfasis adicional en el tema del desarrollo (Singer, 1995). En ese marco se crearon el Banco Mundial y el FMI. Mientras el primero ofrecería créditos a largo plazo para promover el desarrollo, el Fondo tenía como misión original asistir transitoriamente a los países que mostraran desequilibrios en sus balanzas de pago mediante la entrega de créditos, ${ }^{6}$ garantizar el cumplimiento del compromiso por parte de los países de no imponer controles de cambios ni prácticas cambiarias discriminatorias y establecer las pautas centrales del orden monetario internacional. Para esto, se promovió instaurar un sistema de tipos de cambio fijos en relación con el dólar y un precio invariable del oro en 35 dólares la onza; declarar el dólar estadunidense como moneda libremente convertible, y condicionar los ajustes de los tipos de cambios a la aparición de desequilibrios fundamentales en la balanza de pagos (Aglietta y Moatti, 2002, pp. 14-15).

América Latina mostró un gran entusiasmo por el Banco Mundial debido a la posibilidad de acceder a financiamiento a largo plazo, y destacó la oportunidad que otorgaba el FMI a los controles de capital (Helleiner, 2017, pp. 84, 92). No obstante, los economistas latinoamericanos tenían reservas ante el compromiso de fijar los tipos de cambio (Bulmer-Thomas, 2010, p. 299). Por otra parte, la región mostraba una robusta posición externa derivada de un importante volumen de reservas acumulado por las exportaciones de materias primas durante la segunda guerra mundial, y una marcada mejora en los términos de intercambio (Lichtensztejn y Baer, 1989).

Durante su primera década de existencia, el Fondo se limitó a otorgar algunos créditos de baja magnitud a las naciones europeas que encaraban el proceso de reconstrucción de sus economías. No obstante, en esos años algunos países de la región recurrieron al financiamiento del Fondo, aunque limitado al tramo de reserva, una especie de descubierto que alcanzaba $25 \%$ de la cuota aportada por cada país se giraba automáticamente y no incluía condicionalidades. ${ }^{7}$

A mediados de la década de 1950, el modelo de industrialización por sustitución de importaciones encontró obstáculos debido al creciente déficit comercial resultante de una caída de las exportaciones vis a vis un aumento de las importaciones de bienes de capital, la caída de los precios de las materias primas y el aumento de la inflación (Sunkel y Paz, 2004). Ante la ausencia de mercados internacionales de capital lo suficientemente

${ }^{6}$ En respuesta a la demanda británica, la magnitud de sus recursos iniciales casi duplicó la meta de 5000 millones de dólares propuesta por los estadunidenses (Eichengreen, 2000).

${ }^{7}$ Se trató, por orden cronológico, de Chile, Brasil, Costa Rica, Nicaragua, Perú, México y Colombia (datos de Horsefield en Brenta, 2013). 
extendidos, el Fondo reorientó su atención hacia los problemas de financiamiento externo de los países en desarrollo, en particular de América Latina. En 1954 el FMI firmó los primeros acuerdos stand-by (SBA, según sus siglas en inglés) con Perú y México, los cuales dieron el puntapié inicial a una serie de 54 acuerdos con 18 países de América Latina y el Caribe hasta $1961 .{ }^{8}$ Estos acuerdos procuraron controlar la inflación y restablecer el equilibrio externo a costa de políticas ortodoxas, que tuvieron un fuerte impacto negativo sobre la actividad económica y el empleo (Vreeland, 2003), y reforzaron la dependencia (Ugarteche, 2016).

En ese contexto el FMI adoptó el plan Rooth, mediante el cual extendió el plazo de devolución de sus créditos de tres a cinco años y formalizó el acceso al financiamiento por medio de tramos. Si un país quería acceder a un monto mayor a $25 \%$ de su cuota, requería suscribir un $S B A$, un programa de corto plazo (entre doce y 18 meses de duración) ${ }^{9}$ destinado a países que necesitaran superar problemas de balanza de pagos, que preveían desembolsos trimestrales y sujetos al cumplimiento de condicionalidades cuantitativas y/o cualitativas (Frenkel y Avenburg, 2009).

Las condicionalidades no estaban previstas en el convenio constitutivo del FMI, sino que surgieron paralelamente a la difusión de los stand-by. A pesar de su importancia, apenas se incorporaron formalmente al cuerpo normativo del organismo con la primera enmienda del convenio constitutivo en 1969 (Babb y Buira, 2005, p. 62). La combinación de acuerdos SBA y condicionalidades de orientación ortodoxa constituyeron el cuerpo de la doctrina del FMI, que dio sustrato a su actuación en los periodos posteriores (Frenkel y Avenburg, 2009, p. 185).

Un aspecto controversial de la intervención del FMI es la orientación de sus condicionalidades, basadas en el denominado modelo Polak. Desarrollado a mediados de la década de 1950 por el economista Jacques Polak, el modelo constituye la base teórica desde la cual el Fondo diagnostica el estado de cualquier economía que presente un desequilibrio externo y prescribe condiciones. Polak planteaba que en una economía abierta al exterior y con un tipo de cambio fijo, un déficit de balanza de pagos

\footnotetext{
${ }^{8}$ Información estadística relativa a los créditos con base en datos oficiales del FMI History of Lending Arrangements (en adelante HoLA) (IMF, 2017a). Los datos para el artículo fueron extraídos de la web del FMI el 31 de marzo de 2016 para cada uno de los 26 países de América Latina y el Caribe que recibieron desembolsos entre 1954 y 2015 (América Latina -excepto Cuba-, más Barbados, Belice, Dominica, Granada, Haití, Jamaica, San Cristóbal y Nieves, y Trinidad y Tobago) [Recuperado de: http://www.imf.org/external/np/fin/tad/extarr1.aspx]. La base HoLA contiene el detalle de los acuerdos de préstamo concesionario y no concesionario de tramo superior firmados por cada país con el FMI desde 1954, el tipo de crédito, el año de aprobación y de cancelación-expiración del préstamo, y los montos aprobados, efectivamente girados y pendientes de cancelación en derechos especiales de giro.

${ }^{9}$ Posteriormente el FMI extendió la duración de los SBA hasta 36 meses.
} 
indicaba que se estaban absorbiendo demasiados recursos en consumo e inversión en relación con los que el país podía producir. Luego de una serie de simplificaciones, concluía que la expansión rápida del crédito doméstico generaba un déficit externo, que se reflejaría en una caída de las reservas. Así, el modelo postulaba que la cantidad de moneda circulante debía expandirse a una tasa que no superara la del crecimiento real del PIB.

Con base en estos supuestos, las recomendaciones del Fondo para un país que se enfrentaba a un desequilibrio externo se centraban en la depreciación de la moneda nacional y en una política fiscal y monetaria restrictiva, basada en la reducción del gasto público y en la contracción de la base monetaria, que permitiera restablecer el equilibrio al aumentar los saldos exportables y disminuir -al mismo tiempo- las importaciones. Respecto de la apertura externa, el FMI condicionó sus préstamos a la liberalización de las exportaciones, la eliminación de los controles a las importaciones y el reemplazo de los convenios de intercambio y pagos bilaterales por un tipo de cambio único (Woods, 2006, pp. 40-41).

Si bien el modelo atrae por su sencillez, presenta importantes limitaciones. En especial, considera que los desequilibrios externos se explican exclusivamente por factores internos, lo que contradice los postulados del pensamiento estructuralista, en el cual se inspiraban por entonces los modelos de desarrollo de la periferia. En estos países, el déficit externo suele expresar una propensión a la falta crónica de divisas, producto de la combinación de la tendencia al deterioro de los términos de intercambio (Prebisch, 1993) y la existencia de una estructura productiva desequilibrada (Pinto, 1970). En ese marco, una política de ajuste en contexto de crisis no hace sino profundizar el impacto de la recesión y agravar el problema estructural (Braun y Joy, 1981). Aunque a juicio del FMI se trata de una intervención inaceptable en el mercado, la escuela estructuralista encuentra más adecuado resolver el desequilibrio externo mediante el otorgamiento de financiamiento a fin de superar los estrangulamientos a que se enfrentaba el proceso de industrialización, medidas en el ámbito internacional destinadas a mejorar los precios de los productos primarios y una política restrictiva de importaciones que aliente, al mismo tiempo, el desarrollo de una política de sustitución de importaciones (Prebisch en Karner, Love y Pollock, 2001, p. 20)..$^{10}$

\footnotetext{
${ }^{10}$ La insistencia de la Comisión Económica para América Latina y el Caribe, retomada luego por la Conferencia de las Naciones Unidas sobre Comercio y Desarrollo (UNCTAD), respecto a que el origen de los problemas de balanza de pagos en la periferia se encontraba en las condiciones de intercambio desfavorables, llevó a que el FMI constituyera en 1963 la línea de financiamiento compensatorio, mediante la cual buscó mitigar las crisis derivadas de una caída extraordinaria de los ingresos por exportaciones. Pero la falta de clarificación para su otorgamiento y su bajo monto ( $25 \%$ de la cuota), conspiraron contra su utilización generalizada (Lichtensztejn y Baer, 1989).
} 
Ante la necesidad de incorporar capital para impulsar el proceso de industrialización, varios gobiernos de la región promovieron la instalación de empresas multinacionales. La entrada de capital inicial pareció augurar un despegue, pero una estrategia de producción orientada a la provisión de bienes para el mercado interno, junto a una alta propensión a la importación de insumos y la remisión de utilidades, agravaron la restricción externa. Esto alentó a los teóricos de la dependencia que criticaron el carácter políticamente dependiente del desarrollo económico y pugnaron por la conformación de un bloque sociopolítico nacional que lograra mayores grados de autonomía (Cardoso y Faletto, 1998).

La reaparición de la restricción externa implicó un aumento de los créditos otorgados por el FMI hacia el final de la década de 1960, y con él la presión del organismo para profundizar la internacionalización de los procesos productivos y la limitación de la intervención del Estado como motor del desarrollo (Lichtensztejn y Baer, 1989).

Desde 1954 hasta la caída del régimen de Bretton Woods en 1973, el FMI firmó 165 acuerdos stand-by con todos los países de América Latina que integran el organismo (es decir, sin Cuba), más Jamaica, por un total de 23491 millones de dólares constantes (de 2010), ${ }^{11}$ de los cuales se desembolsaron 10972 millones de dólares (IMF, 2017a). Se destacan dos picos de financiamiento, en 1961 y en 1968, por 1228 millones y 1293 millones de dólares respectivamente, coincidentes con los dos ciclos de crisis externas mencionados antes (véase gráfica 1). En cuanto a los desembolsos recibidos, Colombia encabeza la lista con créditos por 1886 millones de dólares, seguido por Argentina, Chile, Brasil y Perú (véase cuadro 1).

\section{ALEJAMIENTO ANTE EL AUGE DE LOS MERCADOS INTERNACIONALES}

DE DEUDA (1974-1981)

A partir de la década de 1960, el régimen de Bretton Woods comenzó a mostrar signos de debilidad. El aumento de la productividad de los países europeos y Japón comenzó a presionar sobre la balanza de pagos de Estados Unidos, lo cual se constató en la disminución de su participación en las exportaciones globales de 33\%, en 1950, a 16\%, en 1970 (Arceo, 2011, p. 48). Esto ponía presión sobre el régimen de tipos de cambio fijos y la

\footnotetext{
${ }^{11}$ Para facilitar la comparación, todas las cantidades mencionadas en el texto -que originalmente se encuentran expresadas en derechos especiales de giro- fueron convertidas a dólares constantes de 2010 de acuerdo con el tipo de cambio de mercado, deflactado por el GDP deflator, publicado por el FMI en el International Financial Statistics (IMF, 2017b).
} 


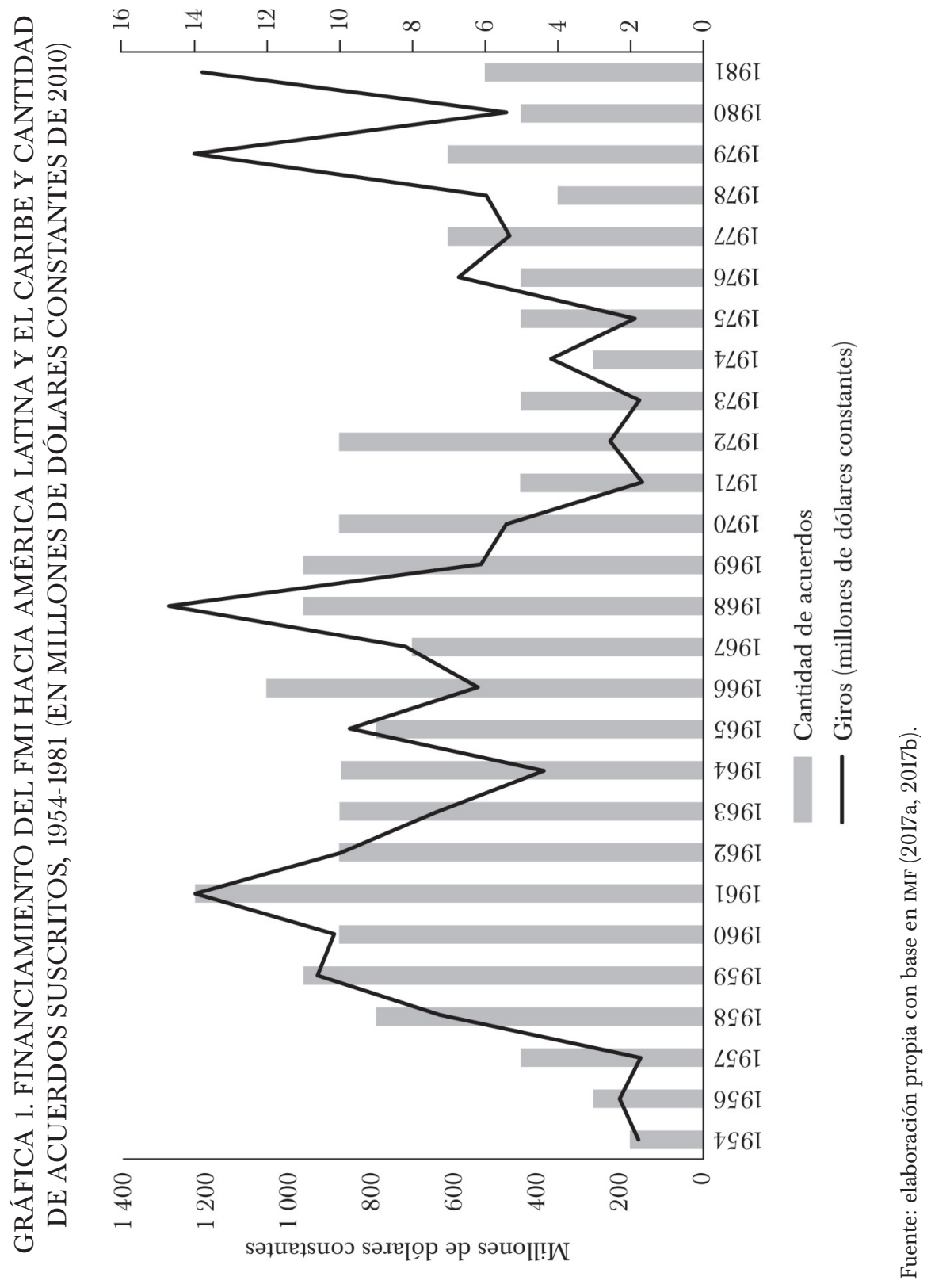




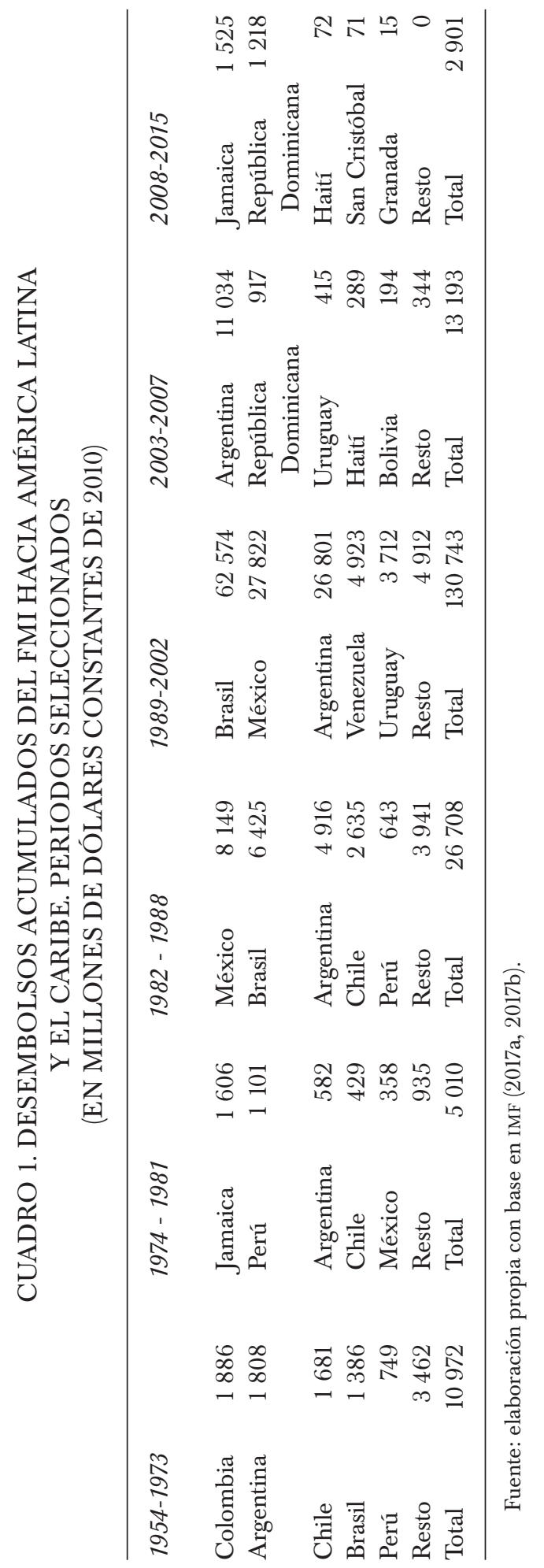


capacidad del dólar estadunidense de mantenerse como medio de pago y de reserva internacional.

$\mathrm{Al}$ creciente déficit comercial se sumaron otros factores: una fuerte salida de capitales, alentada por el interés de las corporaciones estadunidenses en conservar porciones crecientes de sus beneficios en el mercado desregulado de eurodólares, la reticencia de Nixon a la cooperación económica internacional y un creciente debate sobre la necesidad de avanzar para establecer regímenes cambiarios de paridades móviles (crawling peg) para incrementar la flexibilidad. Finalmente, en 1971, Estados Unidos anunció la suspensión temporal de la convertibilidad del dólar con el oro. Durante los dos años subsiguientes, los países europeos mantuvieron la paridad de sus monedas contra el dólar estadunidense, pero en 1973 el gobierno estadunidense determinó una nueva devaluación de su moneda y los países europeos rompieron con las paridades de sus monedas respecto al dólar, lo que dio el golpe final al acuerdo de Bretton Woods (James, 1996, pp. 214 y ss.).

Al tiempo que los países desarrollados afrontaban los cambios en las paridades entre sus monedas, la Organización de Países Exportadores de Petróleo (OPEP) embargó las ventas de petróleo a Estados Unidos y Holanda como consecuencia de la guerra del Yom Kippur en 1973, lo cual generó la duplicación del precio del barril de petróleo. El aumento de los hidrocarburos repercutió fuertemente en la economía de los países industriales, lo que provocó una desaceleración de la actividad, tensiones inflacionarias, altas tasas de desempleo y el desequilibrio en las balanzas de pagos (Centeno, 1982, p. 252).

Para evitar que los países restringieran las importaciones y devaluaran el tipo de cambio ante el shock petrolero, en 1974 el FMI estableció la oil facility, un servicio financiero especial de baja condicionalidad para asistir a los países que se enfrentaban a problemas de balanza de pagos producto del alza del petróleo (Dell, 1981, p. 158). Sin embargo, la oil facility fue boicoteada por Estados Unidos que pretendía formar un cártel de países consumidores de petróleo, por lo cual de los 80000 millones de dólares (constantes de 2010) previstos, sólo llegó a suministrar poco más de 25000 millones de dólares y fue suspendida definitivamente a mediados de 1976 (Centeno, 1982, p. 274). Once países de América Latina y el Caribe recibieron créditos en el marco de la oil facility por un monto total de 2249 millones; entre ellos se destacan Chile (918 000 000), Uruguay (356 000 000) y Argentina (278 000000$).^{12}$

${ }^{12}$ También recibieron créditos en el marco de la oil facility: Perú, Costa Rica, Jamaica, Panamá, El Salvador, Nicaragua, Haití y Granada (IMF, 1976). 
El financiamiento del FMI fue desplazado por los créditos comerciales de los bancos que recibían el excedente de los países superavitarios (Boughton, 2001, p. 15). La renta extraordinaria de los países de la OPEP $^{13}$ fue reinvertida en bancos comerciales de Estados Unidos y el Reino Unido, que, dado el proceso de estanflación por el que atravesaban las economías avanzadas, impulsaron el primer ciclo de endeudamiento externo en la periferia (Hirschman, 1987). Se estima que los préstamos bancarios netos a los países en desarrollo no exportadores de petróleo entre 1974 y 1978 superaron los 100000 millones de dólares corrientes (Dell, 1981, p. 159).

Los cambios sucedidos en el sistema monetario internacional afectaron la actividad del FMI en varios sentidos. En primer lugar, con la caída del régimen de Bretton Woods, el Fondo perdió su principal función de regulador de los tipos de cambio y tuvo que adaptarse al sistema de tipos de cambios flotantes. Frente a las fluctuaciones del precio del dólar tras la ruptura de las paridades cambiarias de Bretton Woods, las autoridades de Estados Unidos, el Reino Unido, Alemania, Japón, Francia e Italia se reunieron a finales de 1975 en Rambouillet (Francia) a fin de crear un mecanismo cambiario ordenado, aunque sin paridades fijas. A partir de entonces, las cumbres del G7 (los seis países mencionados más Canadá) funcionaron como ámbito de coordinación de las políticas económicas globales y así desplazaron los debates multilaterales que se llevaban a cabo en el FMI (Ugarteche, 2016).

El aumento de la liquidez internacional excluyó el interés por los recursos del FMI, lo que introdujo al organismo en una travesía por el desierto. En estas circunstancias, la actividad financiera del FMI en la región se concentró en economías pequeñas como Granada (a este país por primera vez), Haití y Jamaica, que no podían acceder al mercado de capitales (IMF, 2017a).

En la segunda mitad de la década de 1970, los créditos del FMI apoyaron a las incipientes dictaduras militares latinoamericanas que promovieron reformas neoliberales. El FMI otorgó controvertidos desembolsos a Chile, Uruguay y Argentina, poco después de los golpes de Estado. ${ }^{14}$ Entre 1974 y 1975 el FMI aprobó dos SBA con el gobierno de Pinochet, ${ }^{15}$ por los

${ }^{13}$ En 1973 y 1978, la transferencia de recursos de los países de la Organización para la Cooperación y el Desarrollo Económicos hacia los miembros de la OPEP representó una cifra superior a $2 \%$ del producto interno bruto de los primeros (Centeno, 1982, p. 251).

${ }^{14}$ Acerca de los criterios que utiliza el FMI para considerar legítimo a un gobierno, y por ende elegible para sus créditos, Claudio Loser, ex director del Departamento del Hemisferio Occidental, destaca el pragmatismo diplomático: "Si una autoridad está constituida y reconocida internacionalmente, ya es una contraparte válida. Así es en el mundo diplomático y nadie lo discute" (Tenembaum, 2004, p. 54).

${ }^{15}$ A partir de una estratégica tecnocratización del vínculo, Allende alcanzó cierto grado de colaboración con el FMI, la cual incluyó un crédito en el marco de la línea de financiamiento com- 
cuales desembolsó más de 450000000 de dólares; en ese periodo también acordó un SBA por 73000000 de dólares con el presidente de facto uruguayo Juan María Bordaberry (IMF, 2017a). A comienzos de 1976, mientras se instalaba el terrorismo de Estado y se implantaba un plan de liberalización económica, el FMI aprobó un SBA para Argentina por 942000000 de dólares, por entonces el crédito más grande otorgado a un país latinoamericano (Kedar, 2013, p. 140). ${ }^{16}$ Asimismo, estos tres países concentraron $69 \%$ de los desembolsos realizados en el marco de la oil facility entre 1974 y 1975 (International Monetary Fund [IMF], 1976).

Ante el nuevo escenario económico internacional, en 1974 el FMI creó nuevos servicios de financiamiento, entre los que destaca el de facilidades ampliadas, que ofrecía financiamiento a largo plazo (de tres a cuatro años) en el marco de un programa de reformas estructurales. Mediante este nuevo servicio financiero, el FMI sumó a su modelo convencional de estabilización de corto plazo centrado en variables cuantitativas una mirada de largo plazo atenta a un amplio abanico de transformaciones institucionales, como la reducción de los subsidios y la liberalización comercial y de la cuenta de capital (Babb y Buira, 2005). El acuerdo de facilidades ampliadas más significativo que el FMI aprobó en la región durante este periodo fue el programa trianual con México entre 1977 y 1979, que incluyó financiamiento por 1853 millones de dólares (aunque se desembolsaron sólo 358000000$).{ }^{17}$ Con todo, el giro hacia el neoliberalismo en la región generó que las transformaciones estructurales no se limitaran a este tipo de acuerdos; Brenta, Gracida y Rapoport (2009) observan que el programa económico de la dictadura argentina apoyado por un SBA en 1976 promovía cambios estructurales más profundos que los incluidos en el acuerdo de facilidades ampliadas de México.

Irán suspendió la exportación de petróleo tras la revolución de 1979, que representaba 10\% de las exportaciones globales; esto disparó otro aumento en el precio, que agudizó la recesión económica e incrementó la inflación y el desempleo (Centeno, 1982, p. 226). A fin de controlar la inflación, Estados Unidos produjo una notable contracción monetaria conocida como el shock Volcker (Boughton, 2001, p. 269), que elevó la tasa de interés de 4.61 a 19.08\% entre enero de 1977 y 1981 (Federal Reserve Sys-

\footnotetext{
pensatorio para afrontar el impacto del alza del petróleo (Kedar, 2015). No obstante, el organismo dio un apoyo decisivo al gobierno de facto de Pinochet mediante dos cuantiosos stands by.

${ }^{16}$ En relación con el caso argentino, poco después del golpe de Estado el FMI aprobó el stand by que el gobierno democrático de Isabel Perón negoció desde hacía meses. A continuación, Argentina recibió el equivalente a 1574 millones de dólares de 2010 en créditos de bancos privados extranjeros, que le permitieron estabilizar rápidamente el frente externo (Kedar, 2013, p. 140).

${ }^{17}$ Posteriormente solicitaron el servicio de facilidades ampliadas Jamaica (1978, 1979 y 1981), Haití (1978), Honduras (1979), Dominica (1981) y Costa Rica (1981) (IMF, 2017a).
} 
tem, US, 2017), restringió la liquidez internacional y generó turbulencias financieras, lo cual afectó a los países con posiciones externas más frágiles. En particular se vieron perjudicados los países en desarrollo endeudados en dólares, debido a la apreciación de esta moneda y la caída de los precios de las materias primas (Krugman, Obstfeld y Melitz, 2012, p. 648).

En 1979 los giros del FMI hacia la región aumentaron en más de una vez y media debido a la aprobación de un $S B A$ a Perú por 835000000 de dólares (monto que representó 20\% del valor de las importaciones peruanas de ese año) para apoyar un programa de ajuste ortodoxo que promovió el ajuste del consumo y la apertura comercial frente a la caída de las reservas y el cierre del financiamiento privado (Ugarteche, 1986, p. 283).$^{18}$ Dos años después, el Fondo aprobó un crédito de 1000 millones de dólares a Jamaica (un tercio del valor de sus importaciones en 1981$)^{19}$ para apoyar el plan de estabilización del conservador Seaga, quien poco antes había promovido un golpe de Estado contra el régimen socialdemócrata de Manley (Bernal, 1984). ${ }^{20}$ De este modo, a finales de la década de 1970 y comienzos de la siguiente, el FMI alcanzó niveles de desembolsos reales semejantes a los picos de 1961 y 1968 (véase gráfica 1).

No obstante, a partir del estallido de la crisis de la deuda el Fondo aumentó su intervención financiera en la región, lo cual le permitió aumentar la injerencia política.

\section{LA CRISIS DE LA DEUDA: EL FMI COMO GARANTE (1982-1988)}

A comienzos de la década de 1980 los países deudores enfrentaban un panorama negativo por la combinación de la recesión de la economía mundial, el deterioro de los términos de intercambio, los déficits externos y fiscales, como resultado de la abrupta alza de los servicios de la deuda mencionada precedentemente, y el corte repentino del financiamiento externo privado (Devlin y Ffrench-Davis, 1995) ${ }^{21}$ En este marco, la decla-

${ }^{18}$ En dólares constantes (IMF, 2017b, base 2010).

${ }^{19}$ En dólares constantes (IMF, 2017b, base 2010).

${ }^{20}$ El hecho que los mayores volúmenes de préstamos del periodo fueron otorgados a Perú y Jamaica, países que no necesariamente fueron parte de las experiencias neoliberales paradigmáticas de esta etapa, no implica relativizar el giro novedoso del FMI hacia este paradigma de políticas. Por el contrario, puede pensarse que el hecho de no haber avanzado en la implantación de una liberalización de los flujos de capital, recomendación central del programa neoliberal, limitó el acceso al financiamiento privado durante la primera ola de endeudamiento externo, lo cual obturó la posibilidad de utilizar esa fuente para financiar el desequilibrio de la balanza de pagos (véanse Bernal, 1984 y Ugarteche, 1986, para los casos indicados precedentemente).

${ }^{21}$ En busca de las causas de la crisis económica en la región a principios de la década de 1980, Brooks (2004) indica que, frente a las pobres condiciones financieras y macroeconómicas, además de la débil posición de las finanzas públicas, en muchos países de América Latina la aper- 
ración de la cesación de pagos por parte de México en 1982 dio inicio a la crisis de la deuda latinoamericana, la cual se extendió durante toda la década.

La crisis trajo como novedad el surgimiento de un prestamista de última instancia internacional, constituido por una alianza informal y descentralizada entre los gobiernos del G7, los bancos comerciales más grandes y los principales organismos multilaterales, en particular el FMI, que por medio de su financiamiento procuró evitar o postergar moratorias y cesaciones de pago que ponían en riesgo el sistema bancario internacional (Altimir y Devlin, 1993, p. 339). ${ }^{22}$ En este sentido, el Fondo cumplió tres funciones: proveer financiamiento, a fin de posibilitar el repago de las deudas con el sector privado; coordinar la estrategia de negociación del bloque de acreedores junto al Tesoro y los bancos comerciales, y exigir el cumplimiento de las políticas de ajuste estructural orientadas a generar los recursos que permitieran cancelar las deudas (Frenkel y Avenburg, 2009). $\mathrm{Al}$ respecto, Boughton (2000, p. 286) señala que en esta etapa el FMI se consolidó como manager de la crisis. La ambigüedad del mandato del FMI fue un factor clave que facilitó la adaptación del organismo a los cambios en el escenario económico internacional, en un proceso que Babb (2003) denominó deslizamiento organizacional.

Por primera vez, el FMI definiría una estrategia apoyada en el compromiso conjunto de los deudores y los acreedores privados. Como condición previa a la aprobación de un programa de ajuste para los países endeudados, el FMI exigió a los bancos comerciales la renegociación de los plazos de la deuda atrasada y la inyección de fondos frescos (Boughton, 2001, pp. 275-276), lo cual otorgó a los acreedores privados un poder de veto virtual sobre la aprobación de los créditos del FMI que les permitió imponer cambios en los programas de ajuste (Boughton, 2001, pp. 406-407). En este sentido, 79\% de los acuerdos del FMI suscritos entre 1983 y 1990 incluyeron algún tipo de condicionalidad favorable a los bancos, cuando en el periodo de 1974-1982 ese porcentaje fue de sólo 20\% (Gould, 2003, p. 565).

$\mathrm{El}$ intento de generar un bloque de deudores mediante la conformación del Grupo de Cartagena en 1984 fue erosionado por la estrategia de los acreedores de negociar caso por caso (Boughton, 2000, p. 286), sumado a las urgencias de liquidez que enfrentaban los deudores. Así, los países

\footnotetext{
tura de la cuenta de capital no sólo agravó estas fragilidades, sino también profundizó la crisis y prolongó la recuperación posterior.

${ }^{22}$ En 1986 América Latina tenía un stock de deuda bancaria de 200000000 de dólares corrientes, de los cuales 75000000 de dólares correspondían a bancos estadunidenses (37.5\%), 40000000 de dólares estadunidenses a bancos ingleses (20\%), 30000000 de dólares estadunidenses a bancos japoneses (15\%), y el resto estaba distribuido entre instituciones financieras alemanas, francesas, canadienses y suizas (Sachs y Huizinga, 1987, p. 55).
} 
utilizaron la amenaza de consolidación del bloque como una estrategia para obtener pagos laterales de manera individual, que les permitieran mejorar transitoriamente la crisis externa. Debido a su mayor peso político y su alta exposición con los bancos comerciales, Argentina, Brasil y México consiguieron mejores resultados de esta estrategia en relación con las economías más pequeñas, donde el FMI actuó con mayor severidad (Tussie, 1988, p. 297).

Debido a la gran cantidad y diversidad de bancos comerciales involucrados, estos se vieron beneficiados por la coordinación que asumió el FMI. Sólo en el caso de la deuda externa mexicana eran acreedores más de quinientos bancos localizados en Estados Unidos, Europa, y Japón, entre otras regiones; si bien muchas de estas entidades tenían deudas pequeñas, estas sumas eran lo suficientemente importantes como para impedir que un plan pudiera tener éxito sin su participación (Boughton, 2001, p. 296) (véase gráfica 2).

Inicialmente cumplieron un papel clave los recursos aportados por diversas áreas del gobierno de Estados Unidos (México y Brasil) y los préstamos puente otorgados por el Banco de Pagos Internacionales (México, Argentina, Brasil y Chile) (Boughton, 2001). Frente a la incertidumbre que ocasionaba la situación, los primeros compromisos de restructuración de deuda por parte del conjunto de acreedores no superaron el año de duración. A partir de 1984, con el fin de lograr que los bancos comerciales firmaran acuerdos de reestructuración a largo plazo, el FMI supervisó informalmente las políticas económicas y el desempeño de los países mediante consultas semestrales, más allá del periodo de duración de los programas de crédito (Boughton, 2001, pp. 365-367). No obstante, la implantación de la mayor parte de los programas de ajuste quedó inconclusa; de los 25 arreglos aprobados con los países endeudados entre 1982 y 1985, sólo once se utilizaron plenamente y varios de ellos requirieron modificaciones sustanciales (Boughton, 2001, p. 405). En algunos países se logró restaurar transitoriamente la estabilidad financiera mediante la disminución de las importaciones y no el aumento de las exportaciones; por lo tanto, la producción y el empleo siguieron deprimidos y estancados, lo que provocó un aumento de la conflictividad social (Boughton, 2001, p. 416).

Las jóvenes democracias debieron enfrentarse al creciente descontento social por la incapacidad de restablecer un sendero de crecimiento inclusivo. A su vez, los planes económicos no lograron reducir el peso relativo de la deuda externa, dado que cada ajuste conducía a una disminución del producto bruto, lo cual llevaba a un círculo vicioso recesivo. En el marco de fuertes tensiones monetarias, los países se encararon a procesos inflacionarios y registraron deterioros en la distribución del ingreso, los cuales alentaron recurrentes protestas sociales urbanas conocidas como 

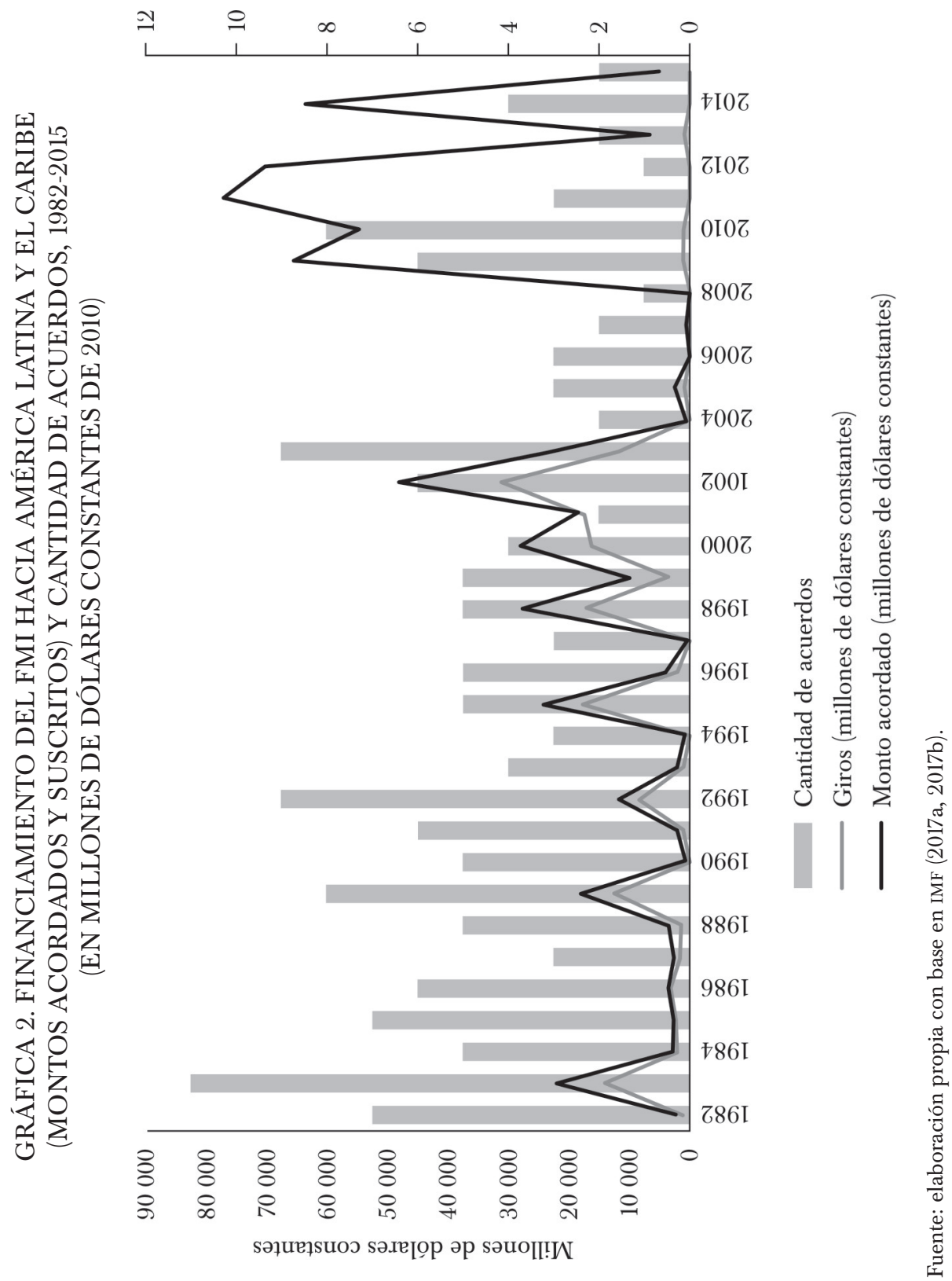
las revueltas del FMI (International Monetary Fund riots) (Ortiz y Béjar, 2013; Walton, 2006).

El fracaso de los planes iniciales de conjugar crecimiento y repago de la deuda alentó la adopción del plan Baker en $1985,{ }^{23}$ que combinó refinanciamientos más extensos por parte de los acreedores y el compromiso de nuevos créditos del Banco Mundial y otras instituciones financieras internacionales, a cambio del establecimiento de programas de ajuste estructural. Durante este periodo, el Banco Mundial destinó una parte creciente de sus créditos a financiar programas, en detrimento de los proyectos de desarrollo (cuyo financiamiento tenía mayores condiciones para su utilización); por su parte, el FMI se involucró en la agenda de desarrollo y profundizó su colaboración con el Banco Mundial para promover -por medio de la condicionalidad cruzada (Feinberg, 1988)- las reformas estructurales basadas en la eliminación de las barreras al comercio, la apertura de la cuenta capital y la privatización de las empresas públicas (Babb y Kentikelenis, 2017; Clifton, Díaz-Fuentes y Lanthier, 2014).$^{24}$ Estas medidas sentaron las bases de las políticas del consenso de Washington, que en los años posteriores fueron promovidas por las instituciones financieras internacionales en tanto paradigma de política transnacional (Babb, 2013).

Durante estos años el FMI mostró un notable incremento de la extensión, magnitud y concentración de su intervención financiera en relación con los periodos previos. Primero, sólo cinco países evitaron someterse a los programas del FMI: Cuba (que no era miembro del FMI), Nicaragua (por oposición a Estados Unidos) y en la región Colombia, Paraguay y Venezuela, que no reestructuraron deudas (Bulmer-Thomas, 2010, p. 428). Segundo, el promedio de los montos acordados por país en relación con las importaciones casi se duplicó respecto a las etapas precedentes, lo que superó $12 \%$ para el total de la región (véase cuadro 2 ) ${ }^{25}$ Tercero, entre 1982 y 1988 el Fondo desembolsó 26708 millones de dólares, contra 5010 millones de dólares que otorgó en el periodo previo; esto implica un promedio de 607000000 de dólares por acuerdo, contra 119000000 de

${ }^{23}$ El plan Baker identificó quince países altamente endeudados, de los cuales diez correspondían a América Latina: Argentina, Bolivia, Brasil, Chile, Colombia, Ecuador, México, Perú, Uruguay y Venezuela. Los otros cinco países eran: Costa de Marfil, Marruecos, Nigeria, Filipinas y Yugoslavia (Boughton, 2001, p. 419).

${ }^{24}$ El solapamiento de funciones provocó tensiones entre ambas instituciones financieras internacionales, de las cuales el programa de 1988 del Banco Mundial con Argentina constituyó un caso paradigmático (Botzman y Tussie, 1991). En este sentido, un año después se firmó el Concordato, mediante el que se clarificó la división de tareas entre el FMI y el Banco Mundial, y se legitimó el liderazgo del primero en temas de macroeconomía y finanzas (Boughton, 2001, pp. 1003-1005).

${ }^{25}$ En el cuadro 4 del anexo se presenta el promedio de los montos acordados por país en relación con el PBI. 
dólares de la etapa previa, un salto de cinco veces. Por último, la parte sustantiva de los créditos se concentró en los países de mayor peso económico, toda vez que requerían una magnitud de capital mayor para afrontar la crisis de la deuda. Esto permite identificar dos grupos en términos del financiamiento recibido: las economías grandes (México, Brasil, Argentina y, en menor medida, Chile) concentraron $83 \%$ del financiamiento, y los 16 países restantes, cuya porción no superó en ningún caso $2 \%$ del total de desembolsos. ${ }^{26}$ Cabe señalar el contraste con la distribución más equitativa observada entre 1954 y 1973, donde Colombia, el primero en recepción de créditos, concentró sólo 17\% (véanse cuadros 1 y 3).

\section{NeOLIBERALISMO Y SALVATAJES FINANCIEROS (1989-2002)}

A finales de la década de 1980 el intento del plan Baker por conjugar el repago de la deuda externa con crecimiento había fracasado. Los recurrentes atrasos e incumplimientos ponían en riesgo la estabilidad del sistema bancario internacional. Por otra parte, los organismos internacionales comenzaron una política selectiva de otorgamiento de créditos a países que tenían atrasos en sus pagos o no habían concluido los acuerdos de refinanciación con los bancos, lo que erosionaba la cartelización de los acreedores (Buckley, 1997).

Nicholas Brady, el secretario del Tesoro de la recién asumida administración de George H. W. Bush (padre), anunció un plan de reestructuración que consistió en un canje voluntario de los créditos contraídos con bancos comerciales por títulos de deuda soberanos a largo plazo con descuento, respaldados con la adquisición de bonos del Tesoro de Estados Unidos. El FMI otorgaría créditos que facilitarían la suscripción de las garantías por parte de los deudores (Frenkel y Avenburg, 2009). ${ }^{27}$ El plan Brady permitió que los deudores salieran del default y la atomización de los acreedores, con lo que se eliminó el riesgo que pesaba sobre los bancos privados. Asimismo, determinó una transformación sustancial en la composición de

${ }^{26}$ El FMI estableció nuevas modalidades de préstamo para los países de bajos ingresos: servicio de ajuste estructural (1986), servicio de ajuste estructural reforzado (1987) y servicio de crédito ampliado (1988). A través de ellas abrió una ventanilla para que los países con economías más pequeñas accedieran a fondos concesionales. A pesar de que estas facilidades extendían los plazos, mantenían la condición de instaurar un programa de ajuste estructural. En 1986 el FMI desembolsó fondos con la modalidad de servicio de ajuste estructural a: Bolivia, Haití y Dominica, entre otros (IMF, 2017a).

${ }^{27}$ Monteagudo (1994) estima la reducción de la deuda externa en los países de América Latina en 25000 millones de dólares, casi 6\% del total del stock de deuda. Pero si se toma en cuenta el impacto del nuevo financiamiento, la deuda nominal prácticamente se mantuvo sin cambios (p. 80). 


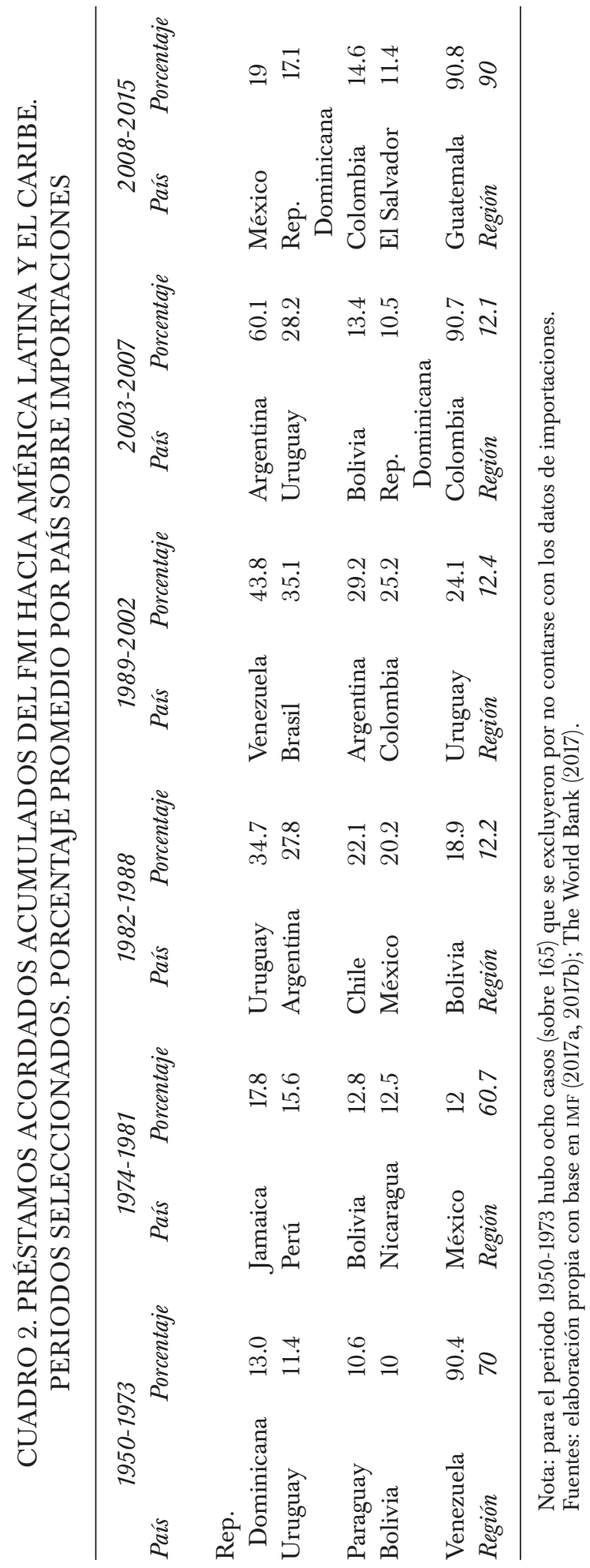




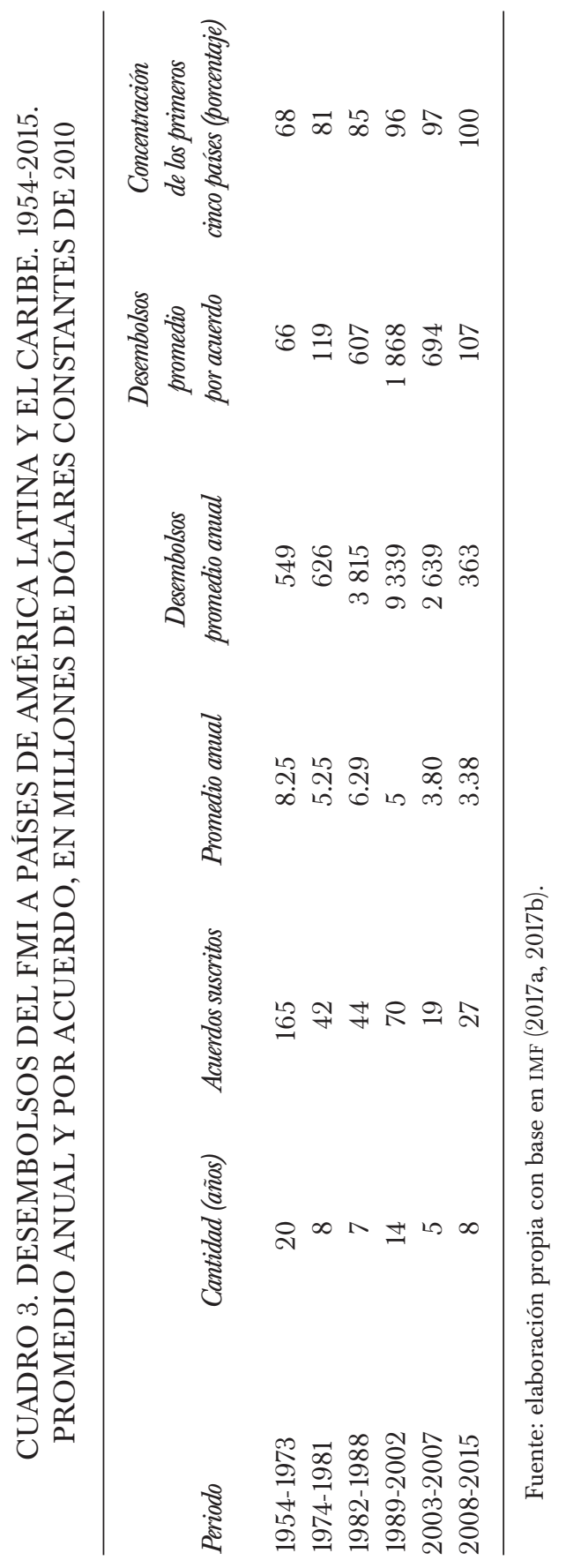


la deuda y los actores involucrados en esta. A partir de este momento la deuda externa estuvo compuesta en su mayoría por títulos que impulsaron el desarrollo de los mercados secundarios de deuda.

Alentada por la mejora en el perfil de la deuda y un nuevo ciclo de alta liquidez internacional, América Latina se incorporó a la segunda ola de la globalización financiera. La economía global ingresó en una fase de reducción de las tasas de interés y se generó un abundante flujo de capitales hacia los países en desarrollo. La caída de los regímenes soviéticos y las crisis inflacionarias dieron ímpetu a la extensión casi universal de las reformas pro mercado, cristalizadas en el consenso de Washington.

Según Torre (1998, p. 33), el impulso a las reformas de mercado en la periferia se explica por dos motivos: primero, la expectativa de una salida de la crisis económica frente al agotamiento de las estrategias de desarrollo de posguerra para afrontar los desafíos económicos, entre los que se destacaba la inflación; segundo, las presiones externas de países centrales, las instituciones financieras internacionales y el sector financiero para resolver el problema de la deuda y la posibilidad de acceder a un nuevo financiamiento oficial y privado.

El FMI ocupó un papel decisivo al ofrecer asistencia técnica a las economías del este de Europa para impulsar la transición al capitalismo ${ }^{28}$ y promover las reformas de mercado en los países en desarrollo (especialmente en los países de ingreso bajo) por medio de recomendaciones basadas en su legitimidad como autoridad experta, y de las condicionalidades (Woods, 2006). Esto último conllevó una ampliación en las áreas de incumbencia del FMI, que se reflejaron en un aumento del número y las áreas de política que abarcaba su condicionalidad (Babb y Kentikelenis, 2017). En América Latina instó a los gobiernos a aplicar una serie de reformas que postulaban objetivos tan diversos como liberalizar el comercio, desregular la cuenta de capital y financiera, reestructurar el tamaño y la organización del peso del sector público, privatizar empresas públicas, desregular mercados y flexibilizar los mercados laborales (Babb y Buira, 2005).${ }^{29} \mathrm{El}$ aumento de las condicionalidades estructurales incrementó el poder discrecional del personal del organismo, ya que, por ejemplo, la evaluación del cumplimiento de una reforma del sistema de seguridad social era más compleja que la de una meta de déficit (Babb y Buira, 2005).

Mediante la suscripción de un acuerdo de financiamiento, los gobiernos se comprometían a cumplir un conjunto de condicionalidades

\footnotetext{
${ }^{28}$ Para esto se introdujeron algunas líneas de financiamiento específicas, como el servicio para la transformación sistémica.

${ }^{29} \mathrm{La}$ influencia del FMI fue más exitosa en las reformas como la liberalización de la cuenta de capital o comercial que en otras como las privatizaciones, en las cuales los grupos de presión internos tienen mayor interés y capacidad de influencia (Biglaiser y Rouen, 2011).
} 
que procuraban garantizar el repago de los compromisos financieros. A su vez, el monitoreo constante del Fondo se consideraba ventajoso dado que constituía un sello de aprobación ante el mercado internacional de capitales, por lo que tenía un efecto catalizador sobre el financiamiento privado. No obstante, la evidencia empírica demuestra que el nivel de cumplimiento de las condicionalidades es moderado (Bird, 2002; Dreher, 2009) y los acuerdos del FMI sólo poseen un modesto efecto positivo sobre las inversiones de portafolio, que por cierto son las más volátiles (Bird y Rowlands, 1997).

En el periodo de 1989 y 1994, el FMI distribuyó en 20 países de América Latina y el Caribe más de 24000 millones de dólares. Entre los acuerdos más significativos destacan los giros realizados bajo el servicio de facilidades ampliadas a México (1989, 6928 millones de dólares), Argentina (1992, 7957 millones de dólares), Venezuela (1989, 4258 millones de dólares) y Perú (1993, 1233 millones de dólares) para financiar la entrada al plan Brady. ${ }^{30}$ Como resultado de las reformas y la entrada de capitales, la región tuvo un crecimiento promedio de 3.6\% anual entre 1991 y $1994,{ }^{31}$ aunque la distribución del ingreso y las condiciones sociales empeoraron, merced al repliegue del Estado.

La crisis financiera de México puso en jaque la sostenibilidad del crecimiento basado en las reformas de mercado y la liberalización financiera. $\mathrm{El}$ ingreso de capitales -producto de la rápida desregulación del mercado de capitales (el flujo de capitales privados pasó de 5800 millones de dólares en 1990 a 30300 millones de dólares en 1993) - y la integración comercial mediante el Tratado de Libre Comercio de América del Norte (TLCAN) provocaron una apreciación de la moneda y un aumento del déficit de cuenta corriente que puso en duda la capacidad del Banco de México para mantener la paridad del peso (Joyce, 2012, pp. 96-97). Frente al riesgo devaluatorio, sumado a ciertas dudas sobre la estabilidad política del país producto del levantamiento de Chiapas y el asesinato del candidato presidencial Luis Donaldo Colosio, los capitales se retiraron y se restringió el acceso al crédito internacional, por lo que en diciembre de 1994 las reservas cayeron en más de 24700 millones de dólares (de 2010), casi $75 \%$ de las reservas disponibles a comienzo de año (IMF, 2017b). ${ }^{32} \mathrm{~A}$ fines de 1994 México devaluó 40\% su moneda y acordó un paquete de rescate por 50000 millones de dólares con el Tesoro de Estados Unidos, que además involucró al resto de los países del G7 y a las instituciones financieras

\footnotetext{
${ }^{30}$ Brasil también suscribió un SBA para ingresar al Brady por 2969 millones de dólares, pero se desembolsó menos de 10\% de ese monto (IMF, 2017a).

${ }^{31}$ Datos de CEPAL (2017).

${ }^{32}$ Deflactados por el GDP deflator.
} 
internacionales (Woods, 2006). El FMI acordó un stand-by con México por 24000 millones de dólares, de los cuales se desembolsaron 17000 millones, en lo que fue el primer paquete de rescate de las crisis sistémicas de la década de $1990 .^{33}$

A partir de entonces, el FMI comenzó a actuar como prestamista de última instancia y garante del repago de las deudas externas, lo cual lo alejaba aún más de su papel original de proveedor de financiamiento transitorio ante crisis de liquidez. A fin de asistir a los países frente a las crisis de solvencia, producto de pérdidas de confianza de los mercados financieros, el FMI lanzó el servicio de complementación de reservas y flexibilizó los límites de acceso a su financiamiento. Luego del rescate de México, el FMI otorgó 17140 millones de dólares a Brasil en 1998, 15678 millones de dólares a Argentina entre 2000 y 2001, y 3219 millones y 27844 millones de dólares a Uruguay y Brasil respectivamente, este último el crédito más grande otorgado por el organismo en su historia hasta entonces, para contener el impacto de la crisis argentina.

Durante la larga década de 1990, que comienza con el plan Brady y cierra con los grandes rescates de Brasil, Uruguay y Turquía, el FMI otorgó créditos por poco más de 130000 millones de dólares, un promedio récord de 9339 millones de dólares por año, lo cual implicó un alza de 145\% respecto del periodo 1982-1988. Por otra parte, la caída en el promedio anual de acuerdos acentuó la diferencia entre el monto promedio por acuerdo, de 607000000 de dólares a 1868 millones de dólares, 208\% más. Por último, se profundizó la tendencia a la concentración del financiamiento, ya que los primeros cinco prestatarios recibieron $96 \%$ de los créditos (véase cuadro 3).

Con la recurrencia de las crisis, se agudizaron las críticas a la intervención del FMI, desde el progresismo se le criticaba que aplicara la misma receta para cualquier país, sin importar sus características particulares, y que sus grandes paquetes de financiamiento constituyeran en la práctica un rescate para los acreedores externos. ${ }^{34}$ Por otra parte, los sectores conservadores, que aumentaron su participación en el debate público con la administración de George W. Bush (hijo) en 2001, señalaban que el FMI contribuía al riesgo moral, ya que los paquetes de rescate fomentaban el endeudamiento irresponsable de los países y las malas políticas de crédito

\footnotetext{
${ }^{33}$ Para una caracterización de las crisis sistémicas véase Frenkel (2003).

${ }^{34}$ Desde la izquierda se cuestionó también el impacto general de las políticas inspiradas en el Consenso de Washington: extranjerización y destrucción de los procesos productivos, reprimarización, precarización del empleo y aumento del endeudamiento externo. El FMI imputó el fracaso de estas consecuencias a las deficiencias institucionales y al peso de la corrupción en la región (Arceo, 2002).
} 
de los acreedores privados, que subestimaban el riesgo de incobrabilidad de esos préstamos (Bembi y Nemiña, 2007).

El FMI lanzó una serie de iniciativas entre las que se destacan el servicio para el crecimiento y la lucha contra la pobreza, una línea de crédito concesional y de largo plazo orientada a los países de bajos ingresos, y la promoción de un mecanismo de restructuración de deudas soberanas para limitar el poder de los acreedores, pero que fue desechado, ya que el Fondo actuaba como juez y parte en el proceso (Joyce, 2012, p. 141).

Ante la creciente deslegitimación como organismo capaz de contribuir al orden monetario internacional y evitar las crisis financieras, el organismo ató su suerte al sostenimiento de la convertibilidad en Argentina, por entonces el último país que el Fondo mostraba como ejemplo exitoso de las políticas neoliberales (Bembi y Nemiña, 2007). La fallida intervención del Fondo en la crisis argentina, la mejora de la situación externa como resultado del aumento de los precios de las materias primas y la implantación de regímenes de flotación sucia sostenidos a partir de la política de acumulación de reservas en la periferia alentaron la segunda travesía por el desierto del organismo (Frenkel y Avenburg, 2009).

\section{Auge y REPLIEGUE (2003-2007)}

En los primeros años del siglo XXI, los países de América Latina y el Caribe se beneficiaron por un auge económico alentado por una combinación inusual de factores externos. El acelerado crecimiento de las economías asiáticas, liderado principalmente por China, aumentó la demanda de recursos naturales, lo que acarreó un alza en los precios de las exportaciones de América Latina. Por otra parte, la baja de la tasa de interés promovida por Estados Unidos para mitigar el impacto del estallido de la burbuja puntocom originó un ciclo de alta liquidez internacional (Ocampo, 2011).

En estas circunstancias, la mayoría de los países latinoamericanos, al igual que otros países en desarrollo, aprovecharon el superávit de cuenta corriente para iniciar un proceso de acumulación de reservas internacionales que les otorgó un seguro de liquidez frente a una potencial desestabilización financiera, y les permitió administrar el tipo de cambio. El superávit externo alentó el ingreso de inversiones extranjeras directas e inversiones de portafolio, que reforzaron la balanza de pagos.

La bonanza económica no sólo permitió prescindir de los recursos del FMI, sino incluso cancelar anticipadamente los créditos pendientes. Al igual que el camino iniciado por Rusia, que a comienzos de 2005 adelantó pagos por más de 3000 millones de dólares, Brasil, Argentina y Uruguay cancelaron entre 2005 y 2006 el total de su deuda con el FMI mediante gi- 
ros de más de 26 000, 10000 y 1000 millones de dólares respectivamente. En consecuencia, la cartera total de préstamos del FMI se redujo hacia el final del periodo a poco más de 16000 millones de dólares, de los cuales 46\% estaba concentrado en Turquía y sólo 837000000 de dólares correspondían a países de la región (IMF, 2017a). ${ }^{35}$ Asimismo, los desembolsos del FMI durante este periodo cayeron a mínimos históricos. Luego de los últimos créditos significativos a Argentina en $2004,{ }^{36}$ el FMI sólo realizó desembolsos puntuales a naciones centroamericanas o caribeñas por 1445 millones de dólares (véase cuadro 1). La caída de los ingresos percibidos por cobros de intereses generó un déficit operativo inédito en el organismo, que lo obligó a vender la octava parte de sus tenencias de oro.

En este marco, el FMI se limitó a monitorear la economía a nivel bilateral y multilateral, por medio de las consultas anuales del artículo IV y las perspectivas económicas mundiales semestrales, respectivamente. Asimismo, comenzó a publicar el informe de estabilidad financiera global con el fin de monitorear la evolución del sistema financiero internacional. Sin embargo, ha sido criticado porque se concentró sólo en la situación de los países en desarrollo, sin prestar la debida atención a las economías mayores; en este sentido, se señala que el FMI hizo caso omiso de la inestabilidad financiera global introducida por las políticas monetarias y fiscales de Estados Unidos desde 2001 (Ugarteche, 2016) y la desregulación financiera (Lichtensztejn, 2010, p. 105).

Aprovechando la fortaleza financiera, los países en desarrollo promovieron mejoras en la gobernanza de las instituciones financieras internacionales. Por un lado, procuraron flexibilizar el contenido de las condicionalidades y limitar su alcance, a fin de ampliar los márgenes de autonomía para el diseño de la política económica. En atención a estos reclamos, en la reforma de 2002 el Fondo focalizó las condiciones estructurales en sus áreas centrales de expertise, pero no logró reducir la cantidad ni modificar sus ineficiencias (Jiménez y Lorenzo, 2010, p. 284).

Los países en desarrollo también propiciaron cambios en la representación que poseían en el FMI y el Banco Mundial, a fin de que la estructura de poder de estas instituciones reflejara de manera más adecuada el peso relativo que habían ganado estos países (en especial, China) en la economía internacional. La concentración del poder dentro del FMI, principalmente en manos de los países del G7, condicionaba las decisiones de este organismo a los intereses y posiciones de los países centrales (Woods, 2006). A

\footnotetext{
${ }^{35}$ A modo comparativo, para encontrar un monto menor de créditos pendientes de reembolsos con países de América Latina fuera de este periodo hay que remontarse a 1971 (IMF, 2017a).

${ }^{36}$ Uruguay recibió un desembolso de 421000000 de dólares en 2006, que fue devuelto rápidamente.
} 
fin de revertir esta situación, el FMI llevó adelante un proceso de reformas que logró una demorada y tibia redistribución de $6 \%$ de los votos hacia los países en desarrollo (en especial, los países BRIC, es decir, Brasil, Rusia, India y China) y la obligación de que todos los directores sean designados mediante elección por sus pares, pero mantuvo la posición dominante de Estados Unidos y la sobrerrepresentación de Europa (Larralde, 2015).

\section{CRISIS INTERNACIONAL Y RESURGIMIENTO (2008 A LA ACTUALIDAD)}

La crisis financiera internacional desatada a partir de la quiebra de Lehman Brothers Holdings Inc. en 2008 impactó en los países en desarrollo mediante la restricción financiera y la contracción del comercio. No obstante, las políticas expansivas de China y las medidas monetarias contracíclicas acordadas en las cumbres del G20 de 2008 y 2009 generaron una recomposición inicial de los precios de las materias primas y una reducción inédita de las tasas de interés que alentaron la rápida recuperación de las economías del Cono Sur. En cambio, México y varios países de América Central, cuya economía estaba estrechamente asociada a Estados Unidos, mostraron una recuperación más lenta (Ocampo, 2011).

En este contexto, el FMI se convirtió en un actor central en el escenario internacional por el G20, el nuevo comité a cargo de la gobernanza global (Wade, 2011). Además de resaltar el papel de supervisor de la estabilidad del sistema financiero internacional, se anunció un incremento sustancial de sus recursos para hacer frente a las necesidades financieras de los países afectados por la crisis. El FMI duplicó los niveles de acceso a su financiamiento de 100 a 200\% de la cuota por año y de 300 a $600 \%$ de la cuota total de cada país; eliminó líneas de financiamiento poco utilizadas (véase figura 1) y lanzó la línea de crédito flexible que ofrece financiamiento precautorio ilimitado y sin condicionalidades,${ }^{37}$ y duplicó sus recursos a unos 659000 millones de dólares mediante el aumento de los créditos bilaterales por parte de las potencias, primero, y la reciente aprobación de la décimocuarta reforma de las cuotas, después (Larralde, 2015).

A fin de reducir el estigma asociado a sus préstamos, el Fondo introdujo una serie de modificaciones en su política de condicionalidad por medio de las cuales redujo las condiciones tradicionales (ex post) en los acuerdos,

${ }^{37}$ La línea de crédito flexible es un instrumento precautorio para atender todo tipo de necesidades de balanza de pagos, que está sujeta a una rigurosa evaluación de precalificación. Esto ha llevado a los críticos a argumentar que se trata de créditos precondicionales menos que incondicionales (Grabel, 2011). Hasta el momento sólo México, Colombia y Polonia accedieron a esta línea de crédito, cuyos últimos acuerdos fueron suscritos por dos años y treparon a 88000 millones, 11500 millones y 18000 millones de dólares respectivamente. 
mediante la mayor utilización de criterios de precalificación; eliminó los criterios estructurales de aplicación (performance criteria), y limitó la condicionalidad a sus áreas centrales de expertise, esto es, variables macroeconómicas financieras, monetarias, fiscales y cambiarias. No obstante, continuó el sesgo ortodoxo en sus condicionalidades, lo cual limita el espacio para la aplicación de políticas contracíclicas en los países que suscriben acuerdos (Nemiña, 2010). ${ }^{38}$

En este periodo el Fondo concentró el grueso de su intervención en la periferia de Europa, la región más afectada por la crisis financiera (Joyce, 2012, p. 182). A fines de 2015, el FMI tenía 46427 millones de dólares en créditos pendientes de reembolso con países pertenecientes a la Unión Europea, $58.6 \%$ de su cartera de créditos total, ${ }^{39}$ mientras que para fines de 2007 esa proporción era cero. No obstante, el FMI también incrementó su participación en América Latina y el Caribe. Los flujos netos mostraron un leve incremento en relación con la etapa previa, lo cual llevó el crédito pendiente de reembolso de 837000000 de dólares en 2007 a 1455 millones de dólares en 2014 (con un pico de 2530 millones en 2011), concentrados en naciones caribeñas entre las que figuran Jamaica y República Dominicana (véase cuadro 1). Asimismo, el Fondo realizó su primer préstamo a San Cristóbal y Nieves, el cual coincidió con un programa de cooperación en transparencia fiscal y tributaria entre ese país y la Organización para la Cooperación y el Desarrollo Económicos.

Con todo, el cambio más notorio remite al inusitado aumento de los compromisos de financiamiento del Fondo hacia América Latina (véase gráfica 2). Entre 2009 y 2015, el Fondo aprobó créditos por una cifra récord de 342987 millones de dólares, de los cuales casi 98\% corresponden a los compromisos renovados anual y luego bianualmente con México (303 870 millones) y Colombia (31 150 millones de dólares estadunidenses) en el marco de la LCF (IMF, 2017a). Se trata de dos países muy vinculados de manera económica y política con Estados Unidos respectivamente. Además de que ambos poseen un Tratado de Libre Comercio con este

\footnotetext{
${ }^{38}$ Después de la crisis de 2008 el FMI publicó una serie de conclusiones que procuraban matizar su tradicional enfoque ortodoxo en la política económica. Planteó que la redistribución era benéfica para el crecimiento económico (Ostry, Berg y Tsangarides, 2014), ponderó las ventajas del gasto para restablecer la actividad -aunque reservado a países con margen presupuestario- (Ban, 2014) y de los controles de capital para morigerar el impacto de una crisis financiera (Gallagher, 2014), y sugirió que el neoliberalismo profundizaba la desigualdad, la cual cercenaba el crecimiento (Ostry, Loungani y Furceri, 2016). No obstante, si bien se ha creado espacio para la aplicación de políticas alternativas en el corto plazo (en especial en el campo fiscal y en la regulación de capitales), es difícil interpretar el giro dado hasta el momento como un quiebre en la visión económica ortodoxa tradicional del organismo (Vernengo y Ford, 2014).

${ }^{39} 86 \%$ de esos créditos correspondía a los rescates otorgados a Portugal y a Grecia. Datos del FMI.
} 


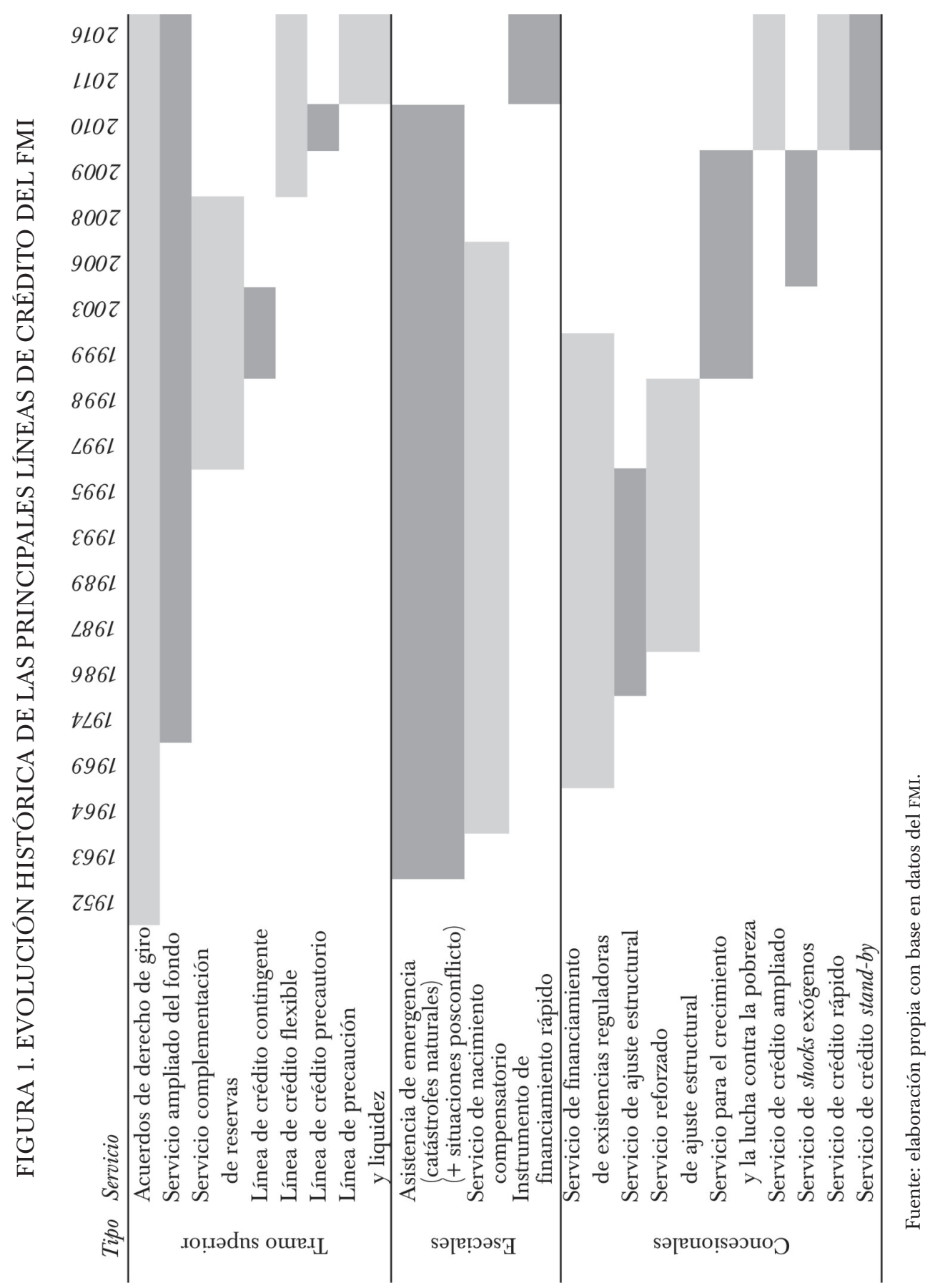


país, México es el segundo destino de las exportaciones estadunidenses (sólo superado por Canadá) ${ }^{40}$ y desde hace más de una década Estados Unidos proporciona una activa colaboración militar en el marco del plan Colombia.

Para los países de la región que no cumplían las condiciones ex ante para acceder a la LCF, el Fondo aprobó programas $S B A$ precautorios, especialmente en los países de Centroamérica: Costa Rica, El Salvador, Honduras y Guatemala. Asimismo, el FMI incrementó su financiamiento a dos países caribeños de bajos ingresos: Granada y Haití.

Hasta el momento, el retorno del FMI a la región muestra tres características. Primero, si bien hubo un incremento de sus desembolsos, su intervención financiera se caracterizó esencialmente por la aprobación de créditos precautorios. Segundo, su intervención se concentró en México y Colombia, con quienes acordó cuantiosos programas precautorios con la línea de crédito flexible, y en Centroamérica y el Caribe, donde aprobó acuerdos stand-by precautorios y realizó desembolsos respectivamente. Se trata de naciones que comparten una vinculación muy estrecha de su ciclo económico con el de Estados Unidos y, por ende, sufrieron en mayor medida el impacto de la crisis subprime en ese país (Ocampo, 2011). Tercero, el Fondo limitó sus desembolsos a países de ingreso bajo. La política preventiva de acumulación de reservas, el acceso al financiamiento en los mercados internacionales de crédito y la asistencia financiera de China, permitieron a las naciones del Cono Sur postergar la solicitud de asistencia al organismo (excepto Colombia, aunque tampoco recibió desembolsos). $\mathrm{Al}$ respecto, aunque no existe un modelo canónico que prediga la participación de los países en los programas del FMI, factores como la recurrencia en la suscripción de acuerdos previos y el incremento en el servicio de la deuda permiten anticipar un cambio en la tendencia (Bird, Mylonas y Rowlands, 2015). En este sentido, la incapacidad de consolidar una red de asistencia financiera regional robusta y la probable alza de las tasas internacionales, con el consecuente impacto sobre el endeudamiento soberano, auguran condiciones que favorecen el retorno del financiamiento del FMI a América del Sur.

\section{ConClusiones}

Con vaivenes, el FMI condicionó activamente la política económica de la región. Si la restricción externa constituye un obstáculo estructural para el desarrollo económico en la periferia, se comprende que el organismo

${ }^{40}$ Datos a 2014 de MIT Media Lab (2017). 
encargado de proporcionar financiamiento ante crisis de balanza de pagos haya tenido una presencia extendida en la economía política de América Latina desde hace más de medio siglo. Esa presencia persistente le otorgó al organismo una capacidad destacada para condicionar el rumbo de la política económica. Esta característica se acentúa en tanto el Fondo es capaz de proveer financiamiento externo cuando los actores privados externos se rehúsan a otorgar créditos y los locales fugan capitales.

En términos estilizados, la intervención del FMI se vuelve más intensa en función del empeoramiento de la balanza de pagos y la ausencia de financiamiento externo privado, multilateral o bilateral disponible para compensarlo. En relación con el caso analizado, pueden distinguirse seis etapas históricas en función de la lógica política que asume la relación. Durante los primeros quince años el Fondo tuvo un papel limitado en la región, debido a la robusta posición externa de los países y las diferencias ideológicas entre el ortodoxo organismo y los equipos económicos embebidos en el estructuralismo latinoamericano, pero la crisis de la industrialización por sustitución de importaciones durante la década de 1960 provocó la primera ola de créditos del Fondo a América Latina. La caída de Bretton Woods y la mayor circulación de capitales alentaron el primer ciclo de endeudamiento externo, que afectó a algunos países (Argentina, Chile) más que a otros (Colombia). En esos años el Fondo se replegó hasta el estallido de la crisis de la deuda, cuando asumió el triple papel de prestamista, coordinador de acreedores y auditor de las políticas de ajuste.

$\mathrm{El}$ aumento de la liquidez internacional y la caída de los regímenes socialistas que parecían augurar el fin de la historia consolidaron el Fondo como promotor de las reformas en pro del mercado y la liberalización financiera. Las crisis sistémicas en las economías emergentes ubicaron al organismo como un prestamista de última instancia, mientras crecían los reclamos sociales al financiamiento excluyente. El auge de las materias primas en conjunto con una oleada de gobiernos progresistas, abrió una etapa de pujante crecimiento acompañado de una persistente mejora en las condiciones de vida de las mayorías. Una vez más el Fondo quedó relegado, esta vez hasta el punto de verse cuestionada su legitimidad política y su viabilidad financiera. Pero ante el estallido de la crisis financiera el G20 lo reubicó como prestamista y vigilante de la economía global.

Es probable que una mayor intervención del FMI en América Latina refuerce el giro político conservador que se produjo en la región, desde la retracción de los gobiernos progresistas que caracterizaron a la década de 2000. Con la excepción de Venezuela, los países de la región han mostrado una vinculación más estrecha con el FMI, que hasta ahora se reflejó en un creciente reconocimiento de la necesidad de implantar un ajuste económico para restablecer la confianza del sector privado y atraer 
la inversión extranjera. La institución también evitó intervenir en el último tramo del litigio argentino con los llamados fondos buitre en los tribunales estadunidenses, que Argentina resolvió con excesivas concesiones de la administración Macri a esos inversionistas (Guzmán, 2016). Un aumento de los préstamos a la región implicaría la aprobación de acuerdos que conducirían a un mayor condicionamiento de las políticas económicas regionales hacia la ortodoxia (Grabel, 2011), con el consiguiente aumento de la desigualdad de ingresos y la profundización de la retracción del sector manufacturero.

El progresivo deterioro de la balanza de pagos de los países de la región, en especial de aquellas economías estrechamente vinculadas con Estados Unidos, posibilitó un nuevo regreso del organismo, que hasta ahora se limita al otorgamiento de créditos precautorios y algunos pocos desembolsos a países del Caribe. No obstante, el crédito concesional proporcionado a Ecuador en abril de 2015 para afrontar los gastos derivados de un terremoto constituye el primer desembolso a un país del Cono Sur en once años y marca un horizonte perturbador para la autonomía financiera regional. 


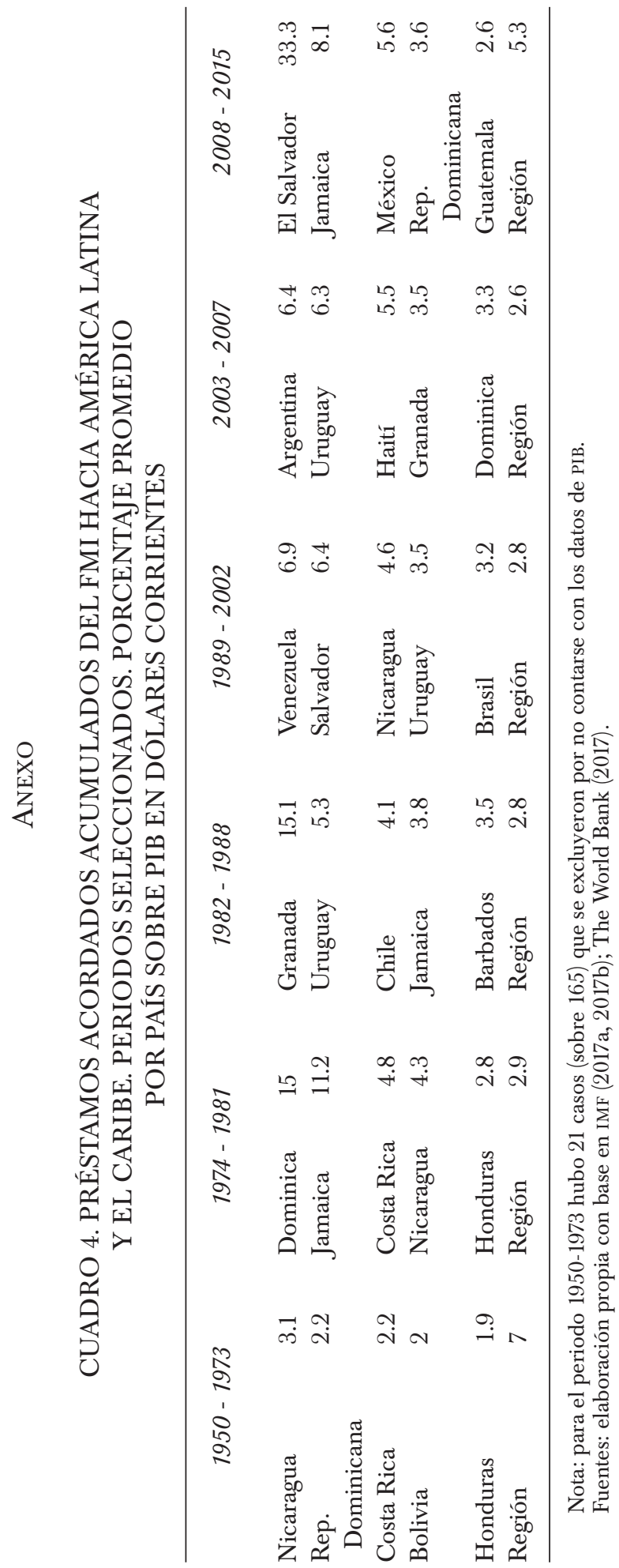




\section{LISTA DE REFERENCIAS}

Aglietta, M. y Moatti, S. (2002). El FMi. Del orden monetario a los desórdenes financieros. Madrid: Akal.

Almeida, P. (2004). Relações internacionais e política externa do Brasil: história e sociologia da diplomacia brasileira. Porto Alegre: Universidade Federal do Rio Grande do Sul.

Altimir, O. y Devlin, R. (1993). An overview of debt moratoria in Latin America. Development Policy Review, 11(4), 339-448. DOI: 10.1111/j.1467-7679.1993.tb00046.x

Arceo, E. (2002). La vida es una moneda. Breve historia de las organizaciones multilaterales de financiamiento: el Banco Mundial y el Fondo Monetario Internacional. Buenos Aires: Instituto de Estudios y Formación/Central de Trabajadores de la Argentina.

Arceo, E. (2011). El largo camino a la crisis. Centro, periferia y transformaciones en la economía mundial. Buenos Aires: Cara o Ceca.

BABB, S. (2003). The IMF in sociological perspective: A tale of organizational slippage. Studies in Comparative International Development, 38(2), 3-27. DOI: 10.1007/ BF02686266

BABB, S. (2013). The Washington Consensus as transnational policy paradigm: Its origins, trajectory and likely successor. Review of International Political Economy, 20(2), 268-297. DOI: 10.1080/09692290.2011.640435

BabB, S. y Buira, A. (2005). Mission creep, mission push, and discretion: The case of IMF conditionality. En A. BUIRA (ed.), The IMF and the world bank at sixty. Londres: Anthem Press.

Babb, S. y Kentikelenis, A. (2017). International financial institutions as agents of neoliberalism. En D. CAhill, M. Konings, M. Cooper y D. Primrose (eds.), The SAGE handbook of neoliberalism. Thousand Oaks: SAGE Publications.

BAN, C. (2014). Austerity versus stimulus? Understanding fiscal policy change at the International Monetary Fund since the great recession. Governance, 28(2), 167-183. DOI: $10.1111 /$ gove.12099

Bembi, M. y Nemiña, P. (2007). Neoliberalismo y desendeudamiento: la relación ArgentinaFMI. Buenos Aires: Capital Intelectual.

Bernal, R. (1984). The IMF and class struggle in Jamaica, 1977-1980. Latin American Perspectives, 11(3). DOI: 10.1177/0094582X8401100304

Biglaiser, G. y Rouen, K. Jr. De (2011). How soon is now? The effects of the IMF on economic reforms in Latin America. Review of International Organizations, 6(2), 189213. DOI: $10.1007 / \mathrm{s} 11558-011-9123-8$

BIRD, G. (2002). The completion rate of IMF programmes: What we know, don't know and need to know. The World Economy, 25(6), 833-847. DOI: 10.1111/1467-9701.00465

BiRD, G., MYlonas, J. y Rowlands, D. (2015). The political economy of participation in IMF programs: A disaggregated empirical analysis. Journal of Economic Policy Reform, 18(3), 221-243. DOI: 10.1080/17487870.2015.1019289 
BIRD, G. y Rowlands, D. (1997). The catalytic effect of lending by the international financial institutions. The World Economy, 20(7), 967-991. DOI: 10.1057/9780230599840_12

Botzman, M. y Tussie, D. (1991). Argentina y el ocaso del plan Baker. Las negociaciones con el Banco Mundial. Boletín Informativo Techint, 265, 63-81.

Boughton, J. (2000). From Suez to Tequila: The IMF as crisis manager. The Economic Journal, 110(460), 273-291. DOI: 10.1111/1468-0297.00501

Boughton, J. (2001). Silent revolution: The International Monetary Fund, 1979-1989. Washington: International Monetary Fund.

Braun, O. y Joy, L. (1981). Un modelo de estancamiento económico: estudio de caso sobre la economía argentina. Desarrollo Económico, 20(80), 585-604. Recuperado de http://www.jstor.org/stable/3466720

Brenta, N. (2013). Historia de la Argentina y el FMI. Buenos Aires: Eudeba.

Brenta, N., Gracida, E. y Rapoport, M. (2009). Argentina, México y el FMi en la crisis de los '70. Ciclos en la Historia, la Economía y la Sociedad, 18, 27-55.

Brooks, S. M. (2004). Explaining capital account liberalization in Latin America: A transitional cost approach. World Politics, 56(3). DOI: 10.1353/wp.2004.0014

BuCKLEY, R. (1997). The facilitation of the Brady Plan: Emerging markets debt trading from 1989 to 1993. Fordham International Law Journal, 21(5), 1802-1889. Recuperado de http://ir.lawnet.fordham.edu/ilj/vol21/iss5/6

Bulmer-Thomas, V. (2010). La historia económica de América Latina desde la Independencia. México: Fondo de Cultura Económica.

Cardoso, F. H. y Faletto, E. (1998). Dependencia y desarrollo en América Latina. México: Siglo XXI.

Centeno, R. (1982). El petróleo y la crisis mundial. Madrid: Alianza.

Clifton, J., Díaz-Fuentes, D. y Lanthier, P. (2014). Utility policy and development since Bretton Woods: The role of multinationals, governments and International Financial Institutions. Utilities Policy, 29, 33-35. DOI: 10.1016/j.jup.2014.03.010

DeLL, S. (1981). El Fondo Monetario Internacional y el principio de condicionalidad. Revista de la CEPAL, 13, 149-161.

Devlin, R. (1989). Debt and crisis in Latin America: The supply side of the story. Princeton: Princeton University Press.

Devlin, R. y Ffrench-Davis, R. (1995). The great Latin America debt crisis: A decade of asymmetric adjustment. Revista de Economía Política, 15(3), 117-142.

Dreher, A. (2009). IMF conditionality: theory and evidence. Public Choice, 141(1), 233267. DOI: $10.1007 / \mathrm{s} 11127-009-9486-\mathrm{z}$

Eichengreen, B. (2000). La globalización del capital. Historia del sistema monetario internacional. Barcelona: Antoni Bosch.

FEINBERG, R. (1988). The changing relationship between the World Bank and the International Monetary Fund. International Organization, 42(3), 545-560, DOI: 10.1017/ S0020818300027739 
Frenkel, R. (2003). Globalización y crisis financieras en América Latina. Revista de la CEPAL, 80, 41-54.

Frenkel, R. y Avenburg, A. (2009). Los cambiantes roles del Fondo Monetario Internacional y América Latina. Desarrollo Económico, 49(194), 179-201. Recuperado de http://www.jstor.org/stable/25702548

Gallagher, K. (2014). Contesting the governance of capital flows at the IMF. Governance, 28(2), 185-198. DOI: 10.1111/gove.12100

García, R. (2008). El Fondo Monetario Internacional y el Banco Mundial en la Argentina. Liberalismo, populismo y finanzas internacionales. Buenos Aires: Lumiere.

GHosh, A. (2013). Exchange rate flexibility in Latin America. Journal of Financial Economic Policy, 5(2), 238-250. DOI: 10.1108/17576381311329689

Gould, E. (2003). Money talks: Supplementary financiers and International Monetary Fund conditionality. International Organization, 57(3), 551-586. DOI: 10.1017/ S0020818303573039

GRABEL, I. (2011). Not your grandfather's IMF: global crisis, "productive incoherence" and developmental policy space. Cambridge Journal of Economics, 35(5), 805-830. DOI: $10.1093 /$ cje/ber012

GuZMán, M. (2016). An analysis of Argentina's 2001 default resolution. CIGI Papers, 110.

Helleiner, E. (2017). The Latin American origins of Bretton Woods. En M. Margulis (ed.), The global political economy of Raúl Prebisch. Nueva York: Routledge.

Hirschman, A. (1987). La economía política del desarrollo latinoamericano. Siete ejercicios en restrospectiva. El Trimestre Económico, 54(216).

Hutchison, M. y Noy, I. (2003). Macroeconomic effects of IMF-sponsored programs in Latin America: output costs, program recidivism and the vicious cycle of failed stabilizations. Journal of International Money and Finance, 22(7). DOI: 10.1016/j. jimonfin.2003.09.007

InTERnATIONAL MONETARy FUnd [IMF] (1976). Annual report of the executive directors for the fiscal year ended April 30, 1976. Washington: IMF.

JAMEs, H. (1996). International monetary cooperation since Bretton Woods. Washington: IMF. Jiménez, J. P. y Lorenzo, F. (2010). Los cambios en el FMi y el impacto en su relación con los países de América Latina. Pensamiento Latinoamericano, 6, 255-283.

JOYCE, J. (2012). The IMF and global financial crises: Phoenix rising? Cambridge: Cambridge University Press.

Karner, D., Love, J. y Pollock, D. (2001). Entrevista inédita a Prebisch: logros y deficiencias de la CEPAL. Revista de la CEPAL, 75, 9-23.

KEDAR, C. (2012). Chronicle of an Inconclusive Negotiation: Perón, the International Monetary Fund, and the World Bank (1946-1955). Hispanic American Historical Review, 92(4), 637-668. DOI: 10.1215/00182168-1727891

KedAr, C. (2013). The International Monetary Fund and Latin America. The Argentina puzzle in context. Philadelphia: Temple University Press. 
KEDAR, C. (2015). Salvador Allende and the International Monetary Fund, 1970-1973: The depoliticisation and technocratisation of Cold War relations. Journal of Latin American Studies, 47(4), 717-747, DOI: 10.1017/S0022216X15000413

Kofas, J. (2002). The sword of Damocles: The IMF, the World Bank, and U.S. foreign policy in Colombia and Chile, 1950-1970. Westport: Praeger.

Krugman, P., Obstfeld, M. y Melitz, M. (2012). Economía internacional: teoría y política. Madrid: Pearson Educación.

Larralde, J. (2015). Concentración de poder en el gobierno del FMI. Análisis de las reformas de 2006, 2008 y 2010. Impacto sobre la Argentina (Tesis de maestría). Universidad de Buenos Aires, Argentina.

Lichtensztejn, S. (2010). Fondo Monetario Internacional y Banco Mundial. Instrumentos del poder financiero. Xalapa: Universidad Veracruzana.

Lichtensztejn, S. y Baer, M. (1989). Fondo Monetario Internacional y Banco Mundial. Estrategias y políticas del poder financiero. Caracas: Nueva Sociedad.

Monteagudo, M. (1994). The debt problem: The Baker plan and the Brady initiative: A Latin American perspective. The International Lawyer, 28(1), 59-81. Recuperado de http://www.jstor.org/stable/40707125

Nemiña, P. (2010). Alcances de la reforma de la política de financiamiento y condicionalidad del FMI. Problemas del Desarrollo. Revista Latinoamericana de Economía, 41(160), 39-66.

NemiÑA, P. (2013). El FMI y la política económica argentina. Observatorio Latinoamericano, 12, 150-163.

OCAmpo, J. A. (2011). ¿Cómo fue el desempeño de América Latina durante la crisis financiera global? Ensayos Económicos, 61/62, 7-33. Recuperado de http://www.bcra. gob.ar/pdfs/investigaciones/61_62_ocampo.pdf

OrTIZ, D. G. y BÉJAR, S. (2013). Participation in IMF-sponsored economic programs and contentious collective action in Latin America, 1980-2007. Conflict Management E Peace Science, 30(5), 492-515. DOI: 10.1177/0738894213499677

Ostry, J., Berg, A. y Tsangarides, C. (2014). Redistribution, inequality, and growth. IMF Staff Discussion Note, SDN/14/02. Washington: International Monetary Fund.

Ostry, J., Loungani, P. y Furceri, D. (2016). Neoliberalism: Oversold? IMF Finance E Development, 53(2), 38-41. Recuperado de http://www.imf.org/external/pubs/ft/ fandd/2016/06/ostry.htm

Pastor, M. (1987). The International Monetary Fund and Latin America: Economic stabilization and class conflict. Boulder: Westview Press.

PinTo, A. (1970). Naturaleza e implicaciones de la "heterogeneidad estructural" de la América Latina. El Trimestre Económico, 37(1).

Prebisch, R. (1993). El desarrollo económico de la América Latina y algunos de sus principales problemas. En R. Prebisch, Obras 1919-1949 (t. IV). Buenos Aires: Fundación Raúl Prebisch.

Remmer, K. (1986). The politics of economic stabilization: IMF standby programs in Latin America, 1954-1984. Comparative Politics, 19(1), 1-24. 
SACHS, J. (1989). Conditionality, debt relief, and the developing country debt crisis. En J. SAchs (ed.), Developing country debt and the world economy. Chicago: Chicago University Press.

SACHS, J. y Huizinga, H. (1987). U.S. Commercial banks and the developing country debt crisis. NBER Working Paper Series, 2455. DOI: 10.3386/w2455.

Scheetz, T. (1986). Peru and the International Monetary Fund. Pittsburgh: University of Pittsburgh Press.

Singer, H. W. (1995). An historical perspective. En P. Streeten, M. U. HaQ, R. Jolly y M. Ul HaQ (eds.), The UN and the Bretton Woods institutions. Nerw challenges for the twenty-first century (pp. 17-25). Basingtoke: Macmillan Press.

Singer, H. W. (1997). Editorial: The golden age of the Keynesian consensus. The pendulum swings back. World Development, 25(3), 293-295. DOI: DOI:.org/10.1016/ S0305-750X $(97) 80789-9$

Stiglitz, J. (2002). El malestar en la globalización. Argentina: Taurus.

SuÁrez, P. (1994). La política financiera internacional de México. Relaciones con el Banco Mundial y el FMI. Comercio Exterior, 44(10), 853-864.

Sunkel, O. y PAZ, P. (2004). El subdesarrollo latinoamericano y la teoría del desarrollo (26a. ed). México: Siglo XXI Editores.

Tenembaum, E. (2004). Enemigos. Argentina y el FMI: la apasionante discusión entre un periodista y uno de los hombres clave del Fondo en los noventa. Buenos Aires: Norma.

TORRE, J. C. (1998). El proceso político de las reformas económicas en América Latina. Buenos Aires: Paidós.

Tussie, D. (1988). The coordination of the Latin American debtors: Is there a logic behind the story? En S. GRIFfith-Jones (ed.), Managing world debt (pp. 282-307). Hertfordshire: Harvester-Wheatsheaf.

Ugarteche O. (1986). El Estado deudor. Economía política de la deuda: Perú y Bolivia 1968-1984. Lima: Instituto de Estudios Peruanos.

Ugarteche O. (2016). Historia crítica del FMI. El gendarme de las finanzas. Buenos Aires: Capital Intelectual.

Vernengo, M. y Ford, K. (2014). Everything must change so that the IMF can remain the same: The world economic outlook and the global financial stability report. Development and change, 45(5), 1193-1204. DOI: 10.1111/dech.12111

VReeland, J. R. (2003). The IMF and economic development. Cambridge: Cambridge University Press.

WADE, R. (2011). Emerging world order? From multipolarity to multilateralism in the G20, the World Bank, and the IMF. Politics E Society, 39(3), 347-378. DOI: 10.1177/0032329211415503

WALtON, J. (2006). Urban protest and the global political economy: The IMF riots. En M. Smith y J. Feagin (eds.), The capitalist city (pp. 354-386). Oxford: Blackwell.

Woods, N. (2006). The globalizers. The IMF, the World Bank and their borrowers. Ithaca: Cornell University Press. 


\section{OTRAS FUENTES}

CEPAL (2017). CEPALStat [online] estadisticas.cepal.org. Recuperado de http://estadisticas.cepal.org/cepalstat/WEB_CEPALSTAT/Portada.asp

Federal Reserve System, US (2017). Effective federal funds rate [FEDFunds] [online]. Recuperado de https://fred.stlouisfed.org/series/FEDFUNDS

IMF (2017a). History of lending arrangements (HoLA) [online]. Recuperado de http://www. imf.org/external/np/fin/tad/extarr1.aspx

IMF (2017b). International financial statistics [online]. Recuperado de http://data.imf.org/ MIT Media Lab (2017). The observatory of economic complexity [online] Recuperado de http://atlas.media.mit.edu/en/

THE WORLD BANK (2017). World development indicators [online] Recuperado de http:// data.worldbank.org/data-catalog/world-development-indicators 